„This is the pre-peer reviewed version of the following article: Bin Cai and Alexander Eychmüller (2018). Promoting Electrocatalysis upon Aerogels. Advanced Materials, 2018, Volume 31, Issue 31, pp. 1804881, which has been published in final form at DOI:10.1002/adma.201804881.

This article may be used for non-commercial purposes in accordance with Wiley Terms and Conditions for Self-Archiving."

\title{
Promoting Electrocatalysis upon Aerogels
}

Bin Cai*, and Alexander Eychmüller*

Dr. Bin Cai ${ }^{\dagger}$, Prof. Dr. Alexander Eychmüller

Physikalische Chemie, Technische Universität Dresden

Bergstraße 66b, 01062 Dresden, Germany

E-mail: bincai@mit.edu; alexander.eychmueller@chemie.tu-dresden.de

${ }^{\dagger}$ Current address:

Research Laboratory of Electronics, Massachusetts Institute of Technology

Cambridge, MA 02139, United States

Keywords: aerogels, electrocatalysis, porous materials, self-assembly, controlled destabilization

Electrocatalysis plays a prominent role in renewable energy conversion and storage, enabling a number of sustainable processes for future technologies. There are generally three strategies to improve the efficiency (or activity) of the electrocatalysts: (i) increasing the intrinsic activity of the catalyst itself; (ii) improving the exposure of active sites; and (iii) accelerating mass transfer during catalysis (both reactants and products). These strategies are not mutually exclusive and can ideally be addressed simultaneously, leading to the largest improvements in activity. Aerogels, as featured by large surface area, high porosity, and self-supportability provide a platform that matches all the aforementioned criteria for the design of efficient electrocatalysts. The field of aerogel synthesis has seen much progress in recent years, mainly thanks to the rapid development of nanotechnology. Employing precursors with different properties enables the resulting aerogel with targeted catalytic properties and improved performances. This report demonstrates the design strategies of aerogel catalysts and reviews their performances for several electrochemical reactions. The common principles that govern electrocatalysis are further discussed for each category of reactions, thus serving as a guide to the development of future aerogel electrocatalysts. 


\section{Introduction}

The efficient conversion of chemical energy to electricity and vice versa, in combination with the utilization of renewable energy resources, is considered to be a viable solution to the fossilfuel crisis. Great expectations are held for technologies such as fuel cells and electrolyzers where the performance relies heavily on the electrochemical conversion processes that can produce and store energy through breaking or forming chemical bonds of molecules like water, hydrogen, oxygen, carbon dioxide, and hydrocarbons. ${ }^{[1]}$ However, the cost-effective deployment of these technologies is severely impeded by the efficiency, selectivity, and durability of the electrocatalysis of the chemical transformations involved. Therefore, the development of improved catalysts and innovative approaches to the catalysts cannot be more urgent. Over the past decades, the combination of theoretical and experimental studies working in concert has provided rational guidance toward the development of next-generation electrocatalysts (i.e. increase the number of active sites and/or increase the intrinsic activity of each active site).

Recent research efforts in this field have led to tremendous improvements of nanostructured electrocatalysts (composed of metals, carbon materials, metal oxides, and sulfides, etc.) in terms of morphology engineering, interface manipulation within hybrid or composite materials, and tuning of electronic structure or surface properties. Among them, the use of three-dimensional (3D) aerogel frameworks as catalysts or catalyst supports represents a rapidly growing branch of research as it combines the desirable bulk properties and processability with the unique nanoscale properties. ${ }^{[2]}$ As a synthetic solid material, aerogels have outstanding and often record-breaking physical properties, including ultralow density (approaching $1.2 \times 10^{-4} \mathrm{~g} \mathrm{~cm}^{-3}$ ), high continuous porosity and extremely large surface areas (up to $1000 \mathrm{~m}^{2} \mathrm{~g}^{-1}$ ), giving them 
immense importance in catalysis and many other applications such as energy storage, piezoelectrics, thermoresistors, and sensors. ${ }^{[3,4]}$

The conventional aerogels are usually obtained based on condensation or polymerization reactions of certain molecular precursors, thus restricting the modification of surface properties and then limiting their further application in catalysis. ${ }^{[5]}$ To tackle this issue, using catalytically active nanomaterials (e.g. nanocrystals, graphene, carbon nanotubes) as the precursors have opened tremendous opportunities for designing aerogels with improved catalysis performance while maintaining the bulk properties. New features often arise during the gelation or assembly of these nanoarchitectures and the resulting aerogel catalysts offer desirable combinations of high exposure of reactive sites, conducting and self-supporting skeletons and straightforward mass transfer pathways. Therefore, the past two decades have witnessed a remarkable progress in the development of carbon nanomaterial-based aerogels, metallic aerogels, metal oxide/sulfite aerogels, and their composite aerogels with improved electrocatalysis performance.

Considering the increasing number of publications dedicated to aerogel-based electrocatalysts, they can be divided into three representative categories: i) heteroatom-doped nanocarbon aerogels based on graphene, carbon nanotubes (CNTs), and organic derived carbons; ii) nanocarbon-based composite aerogels decorated by catalytically active species; iii) pure metallic aerogels built on noble metals and their alloys with transition metals. This report summarizes the design and synthetic strategies of these aerogel catalysts by analyzing different steps during the sol-gel process. Their physical and chemical properties are correlated with the enhancement effects for electrocatalysis. Furthermore, their application in four representative reactions related to fuel cells and water electrolysis were systematically reviewed by organizing and comparing the activities of different aerogels. A better understanding of the synthesis, the resulting structures, and the subsequent performances in electrocatalysis is expected to pave the 
way to a future design of aerogel catalysts. Finally, perspectives on the challenges for future developments of aerogel electrocatalysts are given.

\section{Sol-gel Synthesis and Features of Aerogels}

The explosive studies on heterogeneous catalysis have sparked enormous interests on catalysts with aerogel-like properties, such as large specific surface areas and high porosity. Summarizing the large variety of aerogel materials reported to date, the term "aerogel” can be described as a synthetic solid with meso- and macropores with diameters up to a few hundred nanometers and a porosity of more than $95 \%$ of its volume occupied by gas. ${ }^{[6]}$ Since the first report on aerogels in the 1930s, research on aerogels has been extensively explored by widening the material from inorganic (e.g. metal oxide, carbide, chalcogenide, pure metal) to organic (e.g. polymer, cellulose) and carbon (e.g. CNTs, graphene) materials. ${ }^{[5,6]}$ The general synthesis of aerogels follows the sol-gel process, where a networked monolith (i.e. a hydrogel) separates from the solution, followed by replacement of the solvent with air while retaining the 3D structure.

\subsection{Sol - Selecting Appropriate Building Blocks}

For the conventional aerogels, e.g. silica, metal oxides and organic polymers, the gels are obtained from the gelation of certain molecular precursors. The similar characteristic of those molecules is that they can act as reactants in condensation or polymerization reactions to form sol particles and gels. For instance, metal alkoxides $\mathrm{M}(\mathrm{OR})_{\mathrm{n}}$, which can participate in a hydrolysis-condensation reaction which leads to the formation of "M-O-M" bonds, are widely used as precursors for oxide aerogels. ${ }^{[7]}$ Polymeric species that can form strong “-(C-C) -” covalent bonds are effective precursors for organic aerogels and carbon aerogels, such as resorcinol and formaldehyde. ${ }^{[8]}$ Those precursors hold great potential for large-scale production 
of aerogel, but they usually lead to aerogels with low crystallinity and limit the capability for the modification of surface properties. ${ }^{[3]}$

At this point, colloidal nanomaterials have served as promising precursors for the design and the synthesis of aerogels with desired physical and chemical properties. ${ }^{[6]}$ The use of nanocarbons as precursors, such as graphene (or its oxide) and CNTs, has recently seen a renewed interest for carbon aerogels due to their excellent electrical conductivity, chemical stability, tensile strength, and elasticity ${ }^{[9,10]}$ Owing to their strong adhesion to catalyst particles, nanoparticles (NPs) anchored on graphene or CNTs have also been applied as precursors for hybrid aerogels which combine the features of both NPs and nanocarbons. ${ }^{[11]}$ On the other hand, the pioneering work on quantum dot aerogels in 2005 proved that stable colloidal solution can also act as sol for sol-gel processing, thus opens tremendous opportunities for the design and synthesis of inorganic aerogels. ${ }^{[12]}$ Advances in chemical synthesis have led to numerous kinds of colloidal NP-based electrocatalysts by a rational control of size, morphology, composition, and structure. ${ }^{[13-15]}$ Implementation of these NPs (especially noble metal-based NPs, such as Pt, $\mathrm{Au}, \mathrm{Pd}$, and their alloys) into aerogel synthesis, has led to a very promising class of unsupported aerogel electrocatalysts. ${ }^{[16,17]}$ It should be noted that strong surfactants are detrimental for the followed gelation process (c.f. Section 2.2), mild stabilizers are strongly recommended for the synthesis of NP sols, such as citrate and cyclodextrin.

\subsection{Gelation - Key for 3D Gel Structure}

As discussed in Section 2.1, sols are a stable solution of certain molecules or nanocolloids. The essence of the gelation process is to destabilize the sol in a controllable manner and induce an inter-connection of the precursors forming solid networks out of the liquid solvent.

\subsubsection{Molecular precursors}


Molecular precursors are often utilized for oxide-based aerogels by condensation of the metal salts $\mathrm{MX}_{\mathrm{n}}$ or alkoxides $\mathrm{M}(\mathrm{OR})_{\mathrm{n}}$ forming $3 \mathrm{D}$ solid networks (Figure 1a-c). The condensation process can be catalyzed by proton scavengers (propylene oxide or epoxide, for deprotonation of solvated cations $\left[\mathrm{M}\left(\mathrm{H}_{2} \mathrm{O}\right)_{\mathrm{N}}\right]^{\mathrm{Z}+}$ ) or bases/acids with strong charges (for attacking the $\mathrm{O}\left(\delta^{-}\right)$ atoms from the alkoxy groups). ${ }^{[5]}$ A noteworthy benefit of those molecular precursors is that the corresponding sol enables the mixture of different metal precursors in an atomically homogeneous manner, thus being able to achieve multimetallic oxy-hydroxide gels and oxide aerogels. ${ }^{[18]}$ Perovskite structures can also be obtained by selecting appropriate metal precursors and calcination of the oxide aerogels. ${ }^{[19]}$ Regarding organic aerogels, catalyzed gelation kinetics is also favorable for the polymerization of monomer sols (e.g. slightly basic solutions are needed for the polycondensation of resorcinol or melamine with formaldehyde). ${ }^{[20]}$ Pyrolysis of the organic aerogels at high temperature produces carbon aerogels with electrically conductive networks and mostly retained surface area and porosity. ${ }^{[21]}$

\subsubsection{Graphene and CNTs as precursors}

Unlike the molecular precursors, colloidal nanomaterials are generally stabilized by surfactants to form sols (i.e. stable dispersions). Therefore, the gelation process is similar to a self-assembly strategy which leads to a random interconnection of the isolated nano precursors. Graphene and CNTs are generally well-dispersed in the form of graphene oxide or graphene modified with functionalized groups. At this point, a hydrothermal process that typically occurs in a Teflonlined autoclave is a popular method for fabricating graphene or CNT gels in conjunction with a reduction of the precursors themselves (Figure 1d-e). ${ }^{[22]}$ However, the requirement of high pressures hinders the large-scale synthesis. Mild reduction of graphene oxide with various reducing agents is possible to initiate the self-assembly/gelation process under ambient pressure 
because of the abundance of oxygen-containing groups which enhances the interaction between graphene sheets. ${ }^{[23]}$ Furthermore, cross-linkers can also be used to gelate the graphene sols to form 3D structured gels through electrostatic interaction, hydrogen bonding, or covalent bonding. ${ }^{[24]}$ In addition to the traditional gelation route, direct freezing the sol is a straightforward "gelation” process which creates interconnected structures and porosity based on either ice crystals ${ }^{[25]}$ or emulsion droplets. ${ }^{[26]}$

To improve the physicochemical characteristics, especially the electrochemical properties, heteroatom-doped graphene/CNT aerogels (e.g. $\mathrm{N},{ }^{[27]} \mathrm{Fe},{ }^{[28]} \mathrm{Co}-\mathrm{N},{ }^{[29]} \mathrm{Co} / \mathrm{Fe} / \mathrm{N}^{[30]}$ ) have been fabricated by using correspondingly doped graphene as the precursors. By introducing metal salts to the graphene sol, the hybrid $\mathrm{Fe}_{3} \mathrm{O}_{4}$ /graphene gel can also be achieved by nucleationgrowth of iron oxide NPs on the surface of graphene during the hydrothermal gelation process. $^{[11]}$

\subsubsection{Colloidal NPs as precursors}

One disadvantage of the conventional sol-gel process is its limited number of precursor materials and the poor crystallinity of resulting gel. ${ }^{[6]}$ Colloidal NPs with precisely controlled size, morphology, and composition usually show superior electronic and surface properties beyond their bulk materials. The application of these NPs as precursors for aerogel synthesis bridges the nanoworld with that of materials of macro dimensions while maintaining the nanoscale properties. ${ }^{[31]}$

Gelation of colloidal metal NPs is based on the controlled destabilization of the sol, thus leading to random connection and fusion of the NPs and forming 3D nanowire-based networks (Figure 1g-i). Citrate has been frequently applied for the preparation of NP sols as it can stabilize the metal NPs while keeping a relatively week coordination interaction. Using citrate-stabilized Pd NPs as the sols, Pd gels were obtained by destabilizing the concentrated colloidal sols by either 
heat treatment ${ }^{[32]}$ or complexing with calcium ions. ${ }^{[33]}$ In a similar strategy, gelation of Ag and Pt NP sols were induced by using hydrogen peroxide and ethanol as the destabilizer. ${ }^{[34]}$ It was demonstrated that the gelation kinetics can be controlled by either engineering the ionic strength of the sol $^{[35]}$ or tuning the oxidant/stabilizer molar ratio. ${ }^{[36]}$ It should be pointed out that the concentration step of the as-prepared NPs required for these approaches, however, is usually time-consuming, thus hindering the large-scale synthesis. To this end, spontaneous gelation of the in situ generated NPs with ${ }^{[37]}$ or without ${ }^{[38]}$ the stabilization by cyclodextrins was developed for the fabrication of Pd-Pt gels. Elevated temperature (i.e. $60{ }^{\circ} \mathrm{C}$ )has been proven to accelerate the spontaneous gelation kinetics upon a series of $\mathrm{MCu}$ (with $\mathrm{M}=\mathrm{Pd}$, Pt, or Au) gels. ${ }^{[39]}$ Furthermore, dopamine can destabilize the citrated-capped Au NC sols and induce the gelation process based on its complexation with $\mathrm{Au}{ }^{[40]}$

Once the (aero-)gel structure has been obtained, further modification can be performed to tune the surface properties in order to acquire a hierarchical structure. For example, adding $\mathrm{Pt}^{4+}$ solution into an as-prepared Ag hydrogel induced a galvanic replacement reaction, thus changing the wire-like Ag backbone into alloyed PtAg hollow tubular networks while maintaining the 3D gel structure. ${ }^{[41]}$ Taking advantage of a Cu-mediated electrochemical deposition approach, a thin layer of Pt can be coated on Pd-based aerogels, thus obtaining aerogels with core-shell structure. ${ }^{[42]}$ Besides, electrochemically assisted impregnation has been employed for the decoration of $\mathrm{MnO}_{2} \mathrm{NPs}$ on the pore surface within a graphene gel framework. ${ }^{[43]}$ Annealing of the graphene aerogel in the presence of ammonia produced uniformly $\mathrm{N}$-doped graphene aerogels in a low-cost and scalable way. ${ }^{[44]}$

\subsection{Transforming Wet Gels to Aerogels}

Removal of the solvent from the hydrogel is the final and critical step for producing aerogels. At ambient conditions, the drying process is ruled by high surface tension and capillary forces, 
causing consequently shrinkage and even collapse of the network structure (i.e. xerogels). In this regard, two different drying processes are generally employed: supercritical drying and freeze drying. As for the supercritical drying, the solvent in the gels needs to be replaced with liquid $\mathrm{CO}_{2}$ and then bringing the system to the critical point by increasing the temperature and pressure. Finally lowering the pressure releases the $\mathrm{CO}_{2}$ (from the supercritical fluid to gas) while maintaining a constant temperature. This bypasses the destructive influence of surface tension and preserves the 3D fine structure of the hydrogels with negligible shrinkage.

The freeze drying method is generally applicable for the cryogelated hydrogels. Since the gel solvent is frozen in this method, one should note that the 3D gel structure could be damaged by the formation of solvent crystals. The drying process is based on the sublimation of the frozen solvent (usually vacuum and low temperature are applied), thus preventing the liquid-vapor meniscus. Although it usually results in lower surface area and mesopore volume than those of the supercritical aerogels, the freeze-drying still remains promising because of its economic efficiency. ${ }^{[5]}$ Moreover, freeze drying can also be applied for synthesizing aerogels from strong surfactant capped colloidal NPs. ${ }^{[45]}$

\subsection{Catalytically Beneficial Features}

As discussed in the aforementioned sections, the components for building aerogels can be conductive or catalytically active, thus rendering the aerogels potential candidates for the design of electrocatalysts. As listed in Table 1, aerogels combine the properties of the nanocomponents (e.g. catalytic activity, electric conductivity) with the aerogel properties, such as large surface area (providing more reactive sites), hierarchical porosity (facilitating mass transfer) and selfsupportability. ${ }^{[6,31]}$ An ideal electrocatalyst requires both high activity and durability. High activity relies on increasing the intrinsic activity or exposing more reactive sites. The former can be performed by engineering the electronic structure (e.g. alloy, core-shell structure) or 
synergistic effect (e.g. composite, hybridization) within an aerogel framework. The latter coincides perfectly with the features of the aerogels, as the high surface area and hierarchical porosity (micro-, meso- and macro-pores) facilitate the accessibility of reactants to the active surfaces. Improving the durability can be realized via tailoring the intrinsic property (i.e. backbone of the aerogel) or taking advantage of the structural stability of the aerogel (i.e. replacing or eliminating the catalyst support). Among the reported aerogels, carbon-based aerogels and pure metallic aerogels appear to be among the most promising electrocatalyst candidates.

Carbon materials (e.g. graphene, CNTs, nanofibers) possess good conductivity which lays a strong foundation for the application of their aerogel counterparts in electrocatalysis. During the construction of aerogel structures, surface functionalization (noncovalent or covalent) and heteroatom substitution are believed to modify the local physical and chemical properties, further optimizing their catalytic properties. In addition, the surface chemistry can also be tailored by loading extra catalytically active species (e.g. metal or metal oxide NPs) and then design more complex composite catalysts. In this case, the carbon aerogel serves as a catalyst support, providing electron transfer pathways, synergistic effects and confinement effects. Besides, the graphitized carbon aerogels usually exhibit better stabilities than carbon black, such as graphene or CNTs. ${ }^{[46]}$ It is established that the synergistic effects between the alien species and the nanocarbon aerogel make these composite catalysts more active and stable during electrocatalytic applications. ${ }^{[47]}$

Due to the high intrinsic activity, NPs of noble metals have been extensively studied in various morphologies, structures, and compositions. ${ }^{[48]}$ In most cases, those nanocatalysts are supported on carbon black and rely on its high surface area to obtain adequate dispersion of active sites. ${ }^{[49]}$ However, carbon black corrodes under high potential conditions which are partially responsible for the insufficient durability. ${ }^{[50]}$ Assembly of these NPs into unsupported aerogel frameworks 
provides opportunities to overcome this issue and are potentially less susceptible to other degradation phenomena, such as catalyst particle migration, dissolution, and Ostwald ripening, due to their extended surfaces. ${ }^{[51]}$ It should be noted that dealloying-derived porous metal foams also possess properties such as $3 \mathrm{D}$ continues metallic backbone, high porosity, large surface area and self-supportability. ${ }^{[52-55]}$ Similar to metallic aerogels, these properties are benefiticial to electrocatalysis in terms of both activity and stability. However, the bottom-up synthesis of the metal foams largely limits the further development by hierarchical engineering, while more possibilities remain unexplored on metal aerogels by means of structural engineering of the backbones. $^{[31]}$

For the gas-involved reactions, the integration of electrocatalysts into electrically conductive catalyst layers in membrane electrode assemblies is ultimately required for practical applications. The self-supportability of aerogels leads to a direct contact of the electroactive species with the conductive substrates, thus assuring a good integrity of the catalyst layers. ${ }^{[17]}$

Table 1. Overview of the catalytical benefits of different aerogel-based electrocatalysts

\begin{tabular}{llllll}
\hline \multicolumn{1}{c}{ Aerogel categories } & \multicolumn{1}{c}{$\begin{array}{c}\text { High exposure of } \\
\text { active sites }\end{array}$} & $\begin{array}{c}\text { Hierarchical } \\
\text { porosity }\end{array}$ & $\begin{array}{c}\text { Conducting } \\
\text { skeleton }\end{array}$ & $\begin{array}{c}\text { Catalytically } \\
\text { active skeleton }\end{array}$ & $\begin{array}{c}\text { Self- } \\
\text { supportability }\end{array}$ \\
\hline $\begin{array}{l}\text { Heteroatom-doped carbon aerogels } \\
\text { (e.g. N-graphene aerogel) }\end{array}$ & Yes & Yes & Yes & Yes & Yes \\
$\begin{array}{l}\text { Hybrid aerogels } \\
\text { (e.g. } \mathrm{Fe}_{3} \mathrm{O}_{4} \text { /graphene aerogel) }\end{array}$ & $\begin{array}{l}\text { Yes (but rely on } \\
\text { hybrid materials) }\end{array}$ & Yes & Yes & No & No \\
$\begin{array}{l}\text { Oxide or sulfite aerogels } \\
\text { (e.g. FeCoW-oxide aerogel) }\end{array}$ & Yes & Yes & No & Yes & Yes \\
$\begin{array}{l}\text { Pure metallic aerogels } \\
\text { (e.g. } \mathrm{Pd}_{20} \text { Au-Pt aerogel) }\end{array}$ & Yes & Yes & Yes & Yes & Yes \\
\hline
\end{tabular}

\section{Electrocatalytic Applications}

Nanomaterials often show improved catalytic activity compared with bulk materials. Assembly of them into macroscopic aerogels that maintains the properties from the nanoscale paves a way towards practical applications. ${ }^{[31]}$ The past few decades have seen tremendous advances in the 
development of novel aerogel electrocatalysts for many reactions involving water, hydrogen, oxygen and small organic molecules. This section focuses on several quintessential case studies of electrocatalytic reactions and aims to give an overview of the design principles of aerogel electrocatalysts.

\subsection{Oxygen Reduction Reaction (ORR)}

The electrocatalytic ORR is a challenging reaction in metal-air battery and fuel cell techniques because of its sluggish reaction rate and high overpotentials. For instance, the cathode ORR is six or more orders of magnitude slower than the anode reaction (i.e. hydrogen oxidation), thus largely limiting the fuel cell performance. Therefore, the volume of research on designing highperformance ORR catalysts has been tremendous over the past decades. ${ }^{[56]}$ Depending on the catalytic material, the ORR involves either four-proton-electron transfers to reduce oxygen to water (acidic medium) and $\mathrm{OH}^{-}$(alkaline medium) or a two-proton-electron transfer path with $\mathrm{H}_{2} \mathrm{O}_{2}$ (acidic medium) and $\mathrm{HO}_{2}^{-}$(alkaline medium) as the products. Obviously, a higher selectivity of the four-electron path is desirable for the energy conversion techniques.

To date, fine Pt NPs supported on carbon black (Pt/C) are widely accepted as the state-of-theart ORR electrocatalyst. However, its commercialization is hindered by the high-cost of Pt metal and poor stability. To overcome these issues, various kinds of electrocatalyst materials with low-cost, high activity and durability have been investigated and can be divided into three categories: i) heteroatom substituted carbon materials which are mostly active in alkaline medium; ii) transition metal oxides, carbides and nitrides with relatively lower activity; iii) Pt

and its alloys which remain the most efficient ORR catalysts but limited by its scarcity. ${ }^{\text {[56-58] }}$

\subsubsection{Heteroatom-substituted Carbon Aerogel}


The heteroatom (e.g. N, S, B, F) doped graphitic carbon materials (e.g. graphene, CNTs) are a class of promising electrocatalysts for the ORR, and some of them even outperform the stateof-the-art Pt/C in alkaline medium. Meanwhile, anti-poisoning properties against fuels like CO and $\mathrm{CH}_{3} \mathrm{OH}$ are frequently enhanced on those carbon-based catalysts. ${ }^{[59]}$ Substitution of the C atoms by alien atoms with diverse electronegativity can tune the electronic structure of carbon materials, thus endowing them with enhanced ORR performance in the case of a favorable chemical environment. For example, the strong electron affinity $\mathrm{N}$ atoms increase the positive charge density of the adjacent $\mathrm{C}$ atoms, thus favoring the adsorption of $\mathrm{O}_{2}$ and weakening $\mathrm{O}-\mathrm{O}$ bonding which facilitates the four-electron-reduction of $\mathrm{O}_{2}{ }^{[60]}$ Alternatively, positively charged B dopants can absorb the $\pi^{*}$ electrons and transfer them to chemisorbed $\mathrm{O}_{2}$, thus facilitating the ORR. ${ }^{[61]}$

High specific surface area of the heteroatom-doped carbon aerogels is a key parameter for designing high-performance ORR catalysts, as the skeleton itself represents the active centers. Application of these heteroatom-doped carbon materials often results in the decreased effective surface area because of the $\pi-\pi$ restacking, which can be prevented by designing $3 \mathrm{D}$ aerogel frameworks. For instance, N,B-doped graphene aerogel was synthesized via a two-step method involving a hydrothermal reduction-gelation of graphene oxide together with urea and chitosan and an annealing treatment with boric acid. ${ }^{[62]}$ The resultant N,B-graphene aerogel showed an

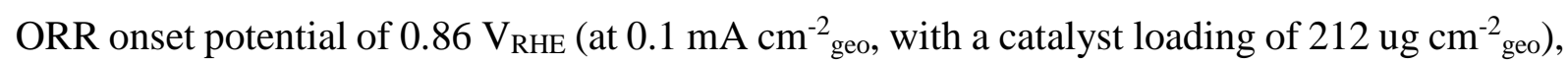
which is already close to the $\mathrm{Pt} / \mathrm{C}$ catalyst. Carbon nanowire aerogels doped by $\mathrm{N}$ and $\mathrm{F}$ have been prepared with a skeleton diameter of $\sim 50 \mathrm{~nm}$ and a specific surface area as high as 768.4 $\mathrm{m}^{2} \mathrm{~g}^{-1} \cdot{ }^{[63]}$ By optimization of the compositions of dopants, the resulting aerogels exhibited an

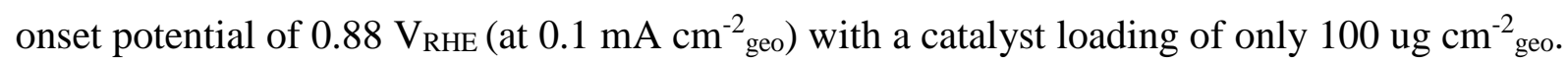
CNTs decorated with $\mathrm{Fe}-\mathrm{N}_{\mathrm{x}}$ active centers can also act as backbones for the design of aerogel catalysts via a hydrothermal approach. ${ }^{[64]}$ The homogeneity of active sites with single-atom 
features brings excellent ORR performance for the Fe-N-CNT aerogel, which even outperforms the $\mathrm{Pt} / \mathrm{C}$ catalyst with lower overpotential and better stability.

On the other hand, designing aerogels based on heteroatom-containing monomers or molecules guarantees a better homogeneity of the dopants. As shown in Figure 2a-d, N,P-doped carbon aerogels were fabricated via pyrolysis of polyaniline aerogel synthesized in the presence of phytic acid. ${ }^{[65]}$ Besides its outstanding ORR performance from RDE tests, the Zn-air battery using this aerogel as the air electrode demonstrated an open circuit potential of $1.48 \mathrm{~V}$ with a specific capacity of $735 \mathrm{mAh} \mathrm{gzn}^{-1}$.

It should be noted that the heteroatom-doped carbon aerogels usually catalyze the ORR in an alkaline medium which limits their implementation in fuel cells owing to the possible $\mathrm{CO}_{2}$ poisoning of the electrolyte. As listed in Table 2, the research on heteroatom-doped carbon aerogel catalysts in acidic fuel cells remains a challenge and still provide much room for improvement. Although those aerogel catalysts possess a high specific surface area (i.e. more active sites), high loadings for the electrode preparation seems to be required to obtain decent ORR performance. However, this would lead to an increase in the thickness of the catalyst layer of a fuel cell, which often induces a potential drop and decreases the cell performance.

Table 2. Overview of the ORR performance of different aerogel electrocatalysts measured on a rotation disk electrode in $\mathrm{O}_{2}$-saturated solutions with a rotation rate of $1600 \mathrm{rpm}$ at a scan rate of $10 \mathrm{mV} \mathrm{s}^{-1}$ (if not specified). Combined with the varying loadings of aerogel electrocatalysts, onset potentials at $1 \mathrm{~mA} \mathrm{~cm}^{-1}$ geo and current densities at 0.8 or $0.9 \mathrm{~V}_{\mathrm{RHE}}$ are adapted to compare the efficiency of different aerogel electrocatalysts (as it is difficult to acquire electrochemical surface areas for non-Pt catalysts). Potentials are all referenced with RHE in order to integrate the alkaline and acid conditions. The aerogel electrocatalysts are divided into three groups, i.e. heteroatom-doped carbon aerogels, hybrid aerogel catalysts, Pt-containing, towards a better understanding of the improvement factor of aerogel catalysts.

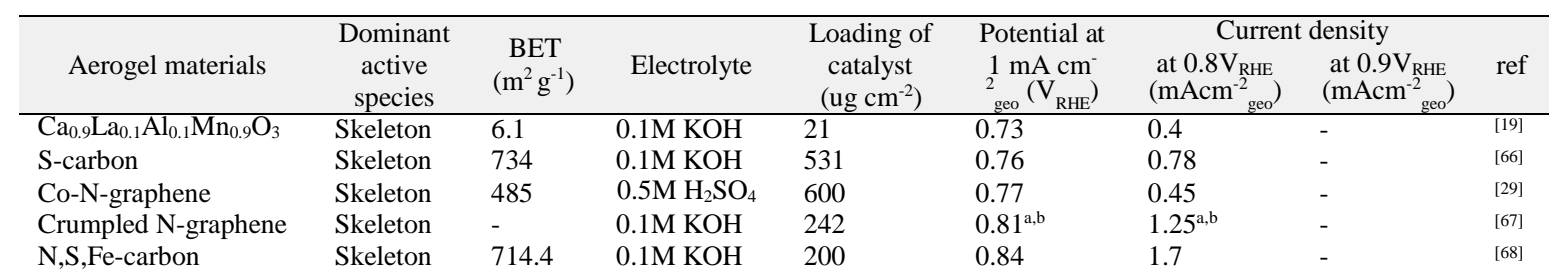




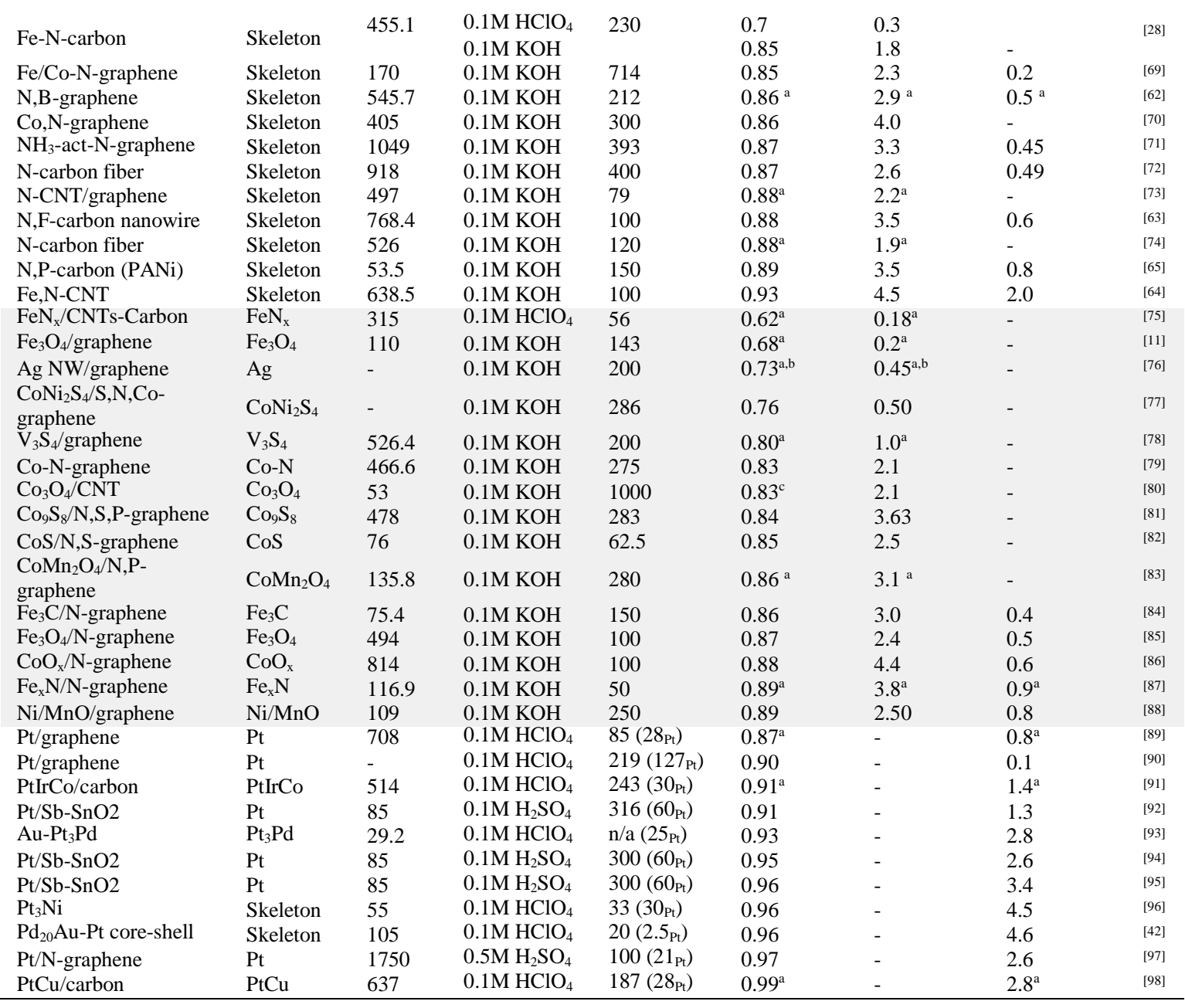

${ }^{\text {a }}$ Potential (vs RHE) was converted from the original data that compared with Ag/AgCl, NHE and SCE.

${ }^{\mathrm{b}}$ Scan rate is $50 \mathrm{mV} \mathrm{s}^{-1}$ and ${ }^{\mathrm{c}}$ scan rate is $5 \mathrm{mV} \mathrm{s}^{-1}$.

\subsubsection{Conductive Aerogel as a Support}

Different from the heteroatom-doped carbon aerogels, hybrid aerogel catalysts using aerogels as a support and the active sites rely on the anchored nanomaterials. Enhanced dispersing and stabilizing the active nanomaterials is the essence of the hybrid electrocatalysts. Nanocarbonbased and other conductive aerogels have large surface areas, fast electron-transfer kinetics, high porosity and excellent affinity to inorganic nanocatalysts (e.g. oxides, nitrides), thus serving as an excellent catalyst support. Synergistic effects between the support and catalyst by electronic structure coupling are often observed and further enhance the catalytic activity and stability. 
Graphene aerogel-supported Ni-MnO electrocatalyst was prepared via dispersing tiny Ni-MnO particles in poly(vinyl alcohol) crosslinked graphene hydrogel (Figure 2e-h). ${ }^{[88]}$ The resulting hybrid aerogels exhibit superior bifunctional electrocatalytic performance for both ORR (owing to the $\mathrm{MnO}$ ) and OER (owing to the metallic Ni) in an alkaline medium, which is desirable for metal-air batteries. To further improve the support, N-doping can be introduced to the graphene aerogel via nitridation in ammonia. ${ }^{[87]}$ The $\mathrm{N}$-doped graphene has strong interactions with $\mathrm{Fe}_{\mathrm{x}} \mathrm{N}$ NPs, leading to a decreased charge transfer resistance and a synergistic effect towards ORR. The as-prepared $\mathrm{Fe}_{\mathrm{x}} \mathrm{N} / \mathrm{N}$-graphene aerogel showed an onset potential of $0.89 \mathrm{~V}_{\mathrm{RHE}}$ (at $0.1 \mathrm{~mA}$ $\mathrm{cm}^{-2}$ geo) at a catalyst loading of only $50 \mathrm{ug} \mathrm{cm}^{-2}$ geo. As listed in Table 2, other materials that are catalytically active for ORR have also been hybridized with heteroatom-doped or non-doped graphene or other nanocarbon aerogels, such as transition metal carbides, ${ }^{[86]}$ spinel oxides, ${ }^{[83]}$ metal sulfides. ${ }^{[82]}$

Despite the scarcity of Pt metal, it remains irreplaceable for the production of commercialized low-temperature fuel cells until now. The state-of-the-art Pt/C catalyst utilizes carbon black as the support, which usually degrades during fuel cell operations. Graphene and CNTs have better chemical durability, conductivity and good affinity to metal NPs, thus serves as a promising electrocatalyst supports. ${ }^{[99]}$ In this regard, monodisperse Pt NPs with an average size of $2.8 \mathrm{~nm}$ have been supported on N-doped graphene aerogel, leading to a specific surface area as high as $1750 \mathrm{~m}^{2} \mathrm{~g}^{-1}$ (while Vulcan XC-72 carbon black is $300 \mathrm{~m}^{2} \mathrm{~g}^{-1}$ ). ${ }^{[97]}$ The aerogel structure not only ensures the exposure of active Pt surfaces to $\mathrm{O}_{2}$ and decrease the diffusion pathways of $\mathrm{O}_{2}$ inside the pore channels, but also increases the adsorption and diffusion of $\mathrm{O}_{2}$ in $\mathrm{Pt} / \mathrm{N}$-graphene aerogel catalysts. In a similar way, carbon aerogels were also utilized as the catalyst supports for Pt-based alloys, such as $\mathrm{PtCu}^{[98]}$ and PtIrCo, ${ }^{[91]}$ for the pursuit of high-performance ORR electrocatalysts. 
Carbon-free metal oxides represent an alternative support for ORR catalysts. Among them, Sbdoped tin oxide $\left(\mathrm{SnO}_{2}\right)$ appears to be the most promising support due to its thermal-dynamic stability in fuel cell cathode operating conditions and electronic conductivity $\left(0.12 \mathrm{~S} \mathrm{~cm}^{-1}\right) .{ }^{[94]}$ In this regard, $\mathrm{Sb}-\mathrm{SnO}_{2}$ aerogel with a reasonably high specific surface area of $85 \mathrm{~m}^{2} \mathrm{~g}^{-1}$ (considering the skeleton density of $\mathrm{SnO}_{2}$ ) and a pore size ranging from $20 \mathrm{~nm}$ to $45 \mathrm{~nm}$ have

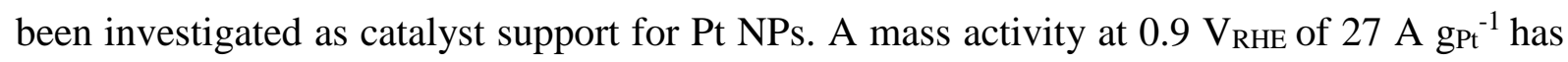
been achieved under optimized conditions. ${ }^{[92]}$

\subsubsection{Pure Metallic Aerogel}

One plausible way to eliminate the support corrosion issues is the utilization of unsupported electrocatalysts. ${ }^{[17]}$ Pure metallic aerogels are of enormous scientific and technological interest owing to their ultralow density, high surface area, and large open interconnected pores. The metallic aerogels combine the noble metal properties (e.g. catalytic activity, electric conductivity) with the large surface area (providing more reactive sites), high porosity (facilitating mass transfer), and self-supportability (eliminating the need for a carbon support). ${ }^{[16]}$

Through a spontaneous gelation pathway, $\mathrm{Pd}_{\mathrm{x}} \mathrm{Pt}_{\mathrm{y}}$ aerogels with a specific surface area of $73 \sim$ $168 \mathrm{~m}^{2} \mathrm{~g}^{-1}$ have been investigated for ORR catalysis. ${ }^{[38]} \mathrm{A}$ mass activity of $1.2 \mathrm{~A} \mathrm{mg}_{\text {metal }}{ }^{-1}$ at $0.9 \mathrm{~V}_{\mathrm{RHE}}$ has been achieved via optimization of the composition, which could be ascribed to the downshift of the d-band center of Pt metal. In a similar strategy, $\mathrm{Pt}_{\mathrm{x}} \mathrm{Ni}$ aerogels were fabricated with a backbone diameter of $\sim 5.6 \mathrm{~nm}$ and a specific surface area of $55 \mathrm{~m}^{2} \mathrm{~g}^{-1} \cdot{ }^{[96]}$ By tuning the $\mathrm{Ni}$ content, the $\mathrm{Pt}_{3} \mathrm{Ni}$ aerogel reveals a 3-fold specific activity increase than commercial $\mathrm{Pt} / \mathrm{C}$ catalysts and a mass activity of $65 \mathrm{~A} \mathrm{~g} \mathrm{gt}^{-1}$ at $0.95 \mathrm{~V}_{\mathrm{RHE}}$. The high intrinsic activity originates from the higher microstrain effects based on the structurally disordered surfaces. ${ }^{[100]}$ Under high potential conditions which can occur during fuel starvation and start-up/shut-down, the $\mathrm{Pt}_{3} \mathrm{Ni}$ 
aerogel shows negligible degradation while the $\mathrm{Pt} / \mathrm{C}$ benchmark displays significant losses of active surfaces. ${ }^{[101]}$ When implemented in polymer electrolyte fuel cell cathodes, it maintains $90 \%$ of the initial activity after an accelerated stress test (vs. $40 \%$ for Pt/C). ${ }^{[102]}$

In an effort to improve the utilization efficiency of Pt metal, a class of $\mathrm{Pd}_{\mathrm{x}} \mathrm{Au}$-Pt core-shell structured metallic aerogels was achieved by coating a Pt shell on the $\mathrm{Pd}_{\mathrm{x}} \mathrm{Au}$ core aerogels with tunable composition (Figure 2i-1). ${ }^{[42]}$ By optimizing the core composition, their mass activity reached a maximum on $\mathrm{Pd}_{20} \mathrm{Au}-\mathrm{Pt}$ with a kinetic current density of $5.25 \mathrm{~A} \mathrm{mg}^{-1} \mathrm{Pt}$ at $0.9 \mathrm{~V}$ RHE, implying an 18.7-fold higher Pt utilization efficiency than that of the Pt/C for the ORR.

\subsection{Fuel Oxidation Reactions}

Fuel cell development utilizing small organic molecules (e.g. methanol, ethanol and formic acid) as fuels has been considered as a favorable option due to the more convenient fuel transportation and refueling conditions compared with hydrogen gas. In addition, direct alcohol fuel cells and direct formic acid fuel cells have the potential for miniaturization towards portable energy sources. The design of high-performance electrocatalysts with fast reaction kinetics and good stability is greatly desirable. The past few decades have seen enormous progress on the design of highly efficient anode electrocatalysts. ${ }^{[103]}$ Among them, noble metals (e.g. Pd, Pt) remain the state-of-the-art material for the construction of anode electrocatalysts.

Table 3. Overview of the electrocatalytic oxidation reaction performances of different aerogel electrocatalysts obtained from three-electrode setups. Mass activities are derived from the peak current density by normalizing to noble metal mass (if not specified). Since the current density relies strongly on the scan rate and the concentration of the reactant, the improvement factor vs. the commercial catalysts is reasonably employed to rank those aerogel catalysts.

\begin{tabular}{|c|c|c|c|c|c|c|c|c|c|}
\hline $\begin{array}{c}\text { Aerogel } \\
\text { materials }\end{array}$ & $\begin{array}{c}\text { Dominant } \\
\text { active species }\end{array}$ & $\begin{array}{c}\text { BET } \\
\left(\mathrm{m}^{2} \mathrm{~g}^{-1}\right)\end{array}$ & $\begin{array}{c}\text { ECSA } \\
\left(\mathrm{m}^{2} \mathrm{~g}^{-1}\right)\end{array}$ & Reactant & Electrolyte & $\begin{array}{l}\text { Scan rate } \\
\left(\mathrm{mV} \mathrm{s}^{-1}\right)\end{array}$ & $\begin{array}{c}\text { Mass activity } \\
\text { (A mg }{ }_{\text {no }}^{\text {ble metal })}\end{array}$ & $\begin{array}{l}\text { Improvement } \\
\text { factor }\end{array}$ & ref \\
\hline PtRu/carbon & PtRu & 382 & 72 & $4.2 \mathrm{M} \mathrm{MeOH}$ & $1.0 \mathrm{M} \mathrm{H}_{2} \mathrm{SO}_{4}$ & 5 & 0.0286 & - & [104] \\
\hline Pt/N-graphene & Pt & 144.3 & 42.2 & $1.0 \mathrm{M} \mathrm{MeOH}$ & $0.5 \mathrm{M} \mathrm{H}_{2} \mathrm{SO}_{4}$ & 50 & 0.903 & - & [105] \\
\hline $\mathrm{Pt} / \mathrm{C} /$ graphene & Pt & - & 70.4 & $0.5 \mathrm{M} \mathrm{MeOH}$ & $0.5 \mathrm{M} \mathrm{H}_{2} \mathrm{SO}_{4}$ & 50 & 0.405 & 0.95 vs. $\mathrm{Pt} / \mathrm{C}$ & [106] \\
\hline $\mathrm{Pt}_{3} \mathrm{Sn}$ & Skeleton & - & 30.9 & $0.5 \mathrm{M} \mathrm{MeOH}$ & $0.1 \mathrm{M} \mathrm{HClO}_{4}$ & 50 & 1.45 & 1.45 vs. $\mathrm{Pt} / \mathrm{C}$ & [107] \\
\hline Pt/graphene & Pt & - & 41.2 & $0.5 \mathrm{M} \mathrm{MeOH}$ & $0.5 \mathrm{M} \mathrm{H}_{2} \mathrm{SO}_{4}$ & 50 & 0.576 & 1.92 vs. $\mathrm{Pt} / \mathrm{C}$ & {$[108]$} \\
\hline
\end{tabular}




\begin{tabular}{|c|c|c|c|c|c|c|c|c|c|}
\hline $\mathrm{Pd}_{83} \mathrm{Ni}_{17}$ & Skeleton & 29.8 & 37.5 & 1.0M MeOH & 1.0M KOH & 50 & 1.11 & 2.2 vs. $\mathrm{Pd} / \mathrm{C}$ & [109] \\
\hline $\mathrm{AuPt}_{5}$ & Skeleton & - & 53.9 & 1.0M MeOH & $1.0 \mathrm{H}_{2} \mathrm{SO}_{4}$ & 50 & 0.51 & 2.3 vs. $\mathrm{Pt} / \mathrm{C}$ & [110] \\
\hline PtIrCo/carbon & PtIrCo & 514 & 61 & $1.0 \mathrm{M} \mathrm{MeOH}$ & $0.1 \mathrm{M} \mathrm{HClO}_{4}$ & 20 & 0.80 & 2.46 vs. $\mathrm{Pt} / \mathrm{C}$ & [91] \\
\hline $\mathrm{Pt} / \mathrm{N}$-graphene & Pt & 281.7 & 90.7 & $0.5 \mathrm{M} \mathrm{MeOH}$ & $0.5 \mathrm{M} \mathrm{H}_{2} \mathrm{SO}_{4}$ & 50 & 0.554 & 4.39 vs. $\mathrm{Pt} / \mathrm{C}$ & [111] \\
\hline $\mathrm{Pt} / \mathrm{C} / \mathrm{SiO}_{2}$ & $\mathrm{Pt}$ & 731 & - & $1.0 \mathrm{M} \mathrm{MeOH}$ & $1.0 \mathrm{M} \mathrm{H}_{2} \mathrm{SO}_{4}$ & 5 & 0.65 & 13 vs. $\mathrm{Pt} / \mathrm{C}$ & [112] \\
\hline $\mathrm{Ni}$ /graphene & $\mathrm{Ni}$ & - & - & $0.1 \mathrm{M} \mathrm{EtOH}$ & $0.1 \mathrm{M} \mathrm{NaOH}$ & 100 & $8.4 \mathrm{~A} \mathrm{~g}^{-1}{ }_{\mathrm{Ni}+\mathrm{C}}$ & - & [113] \\
\hline $\mathrm{Pd}$ & Skeleton & 51.8 & 69 & $1.0 \mathrm{M} \mathrm{EtOH}$ & $1.0 \mathrm{M} \mathrm{KOH}$ & 50 & 7.83 & 2.3 vs. $\mathrm{Pd} / \mathrm{C}$ & \\
\hline $\mathrm{Pd}_{68} \mathrm{Cu}_{32}$ & Skeleton & 30.0 & 37.9 & 1.0M EtOH & $1.0 \mathrm{M} \mathrm{KOH}$ & 50 & 3.47 & 2.9 vs. $\mathrm{Pd} / \mathrm{C}$ & [39] \\
\hline $\mathrm{Pt}_{3} \mathrm{Sn}$ & Skeleton & - & 30.9 & $0.5 \mathrm{M} \mathrm{EtOH}$ & $0.1 \mathrm{M} \mathrm{HClO}_{4}$ & 50 & 1.08 & 3.5 vs. $\mathrm{Pt} / \mathrm{C}$ & [107] \\
\hline $\mathrm{Pt}_{80} \mathrm{Ni}_{20}$ & Skeleton & 67.7 & 46.9 & 1.0M EtOH & $1.0 \mathrm{M} \mathrm{NaOH}$ & 50 & 2.60 & 4 vs. $\mathrm{Pt} / \mathrm{C}$ & [114] \\
\hline $\mathrm{Pd}_{83} \mathrm{Ni}_{17}$ & Skeleton & 95.4 & 55.5 & 1.0M EtOH & $1.0 \mathrm{M} \mathrm{NaOH}$ & 50 & 3.63 & 5.6 vs. $\mathrm{Pd} / \mathrm{C}$ & [115] \\
\hline $\mathrm{Ni}-\mathrm{Pd}_{80} \mathrm{Pt}_{20}$ & Skeleton & 89.1 & 54.7 & 1.0M EtOH & $1.0 \mathrm{M} \mathrm{NaOH}$ & 50 & 4.71 & 7.3 vs. $\mathrm{Pt} / \mathrm{C}$ & [114] \\
\hline $\mathrm{Ni}-\mathrm{Pd}_{20} \mathrm{Pt}_{80}$ & Skeleton & 69.2 & 49.2 & 1.0M EtOH & $1.0 \mathrm{M} \mathrm{NaOH}$ & 50 & 5.15 & 8.1 vs. $\mathrm{Pt} / \mathrm{C}$ & [114] \\
\hline $\mathrm{Ni}-\mathrm{Pd}_{40} \mathrm{Pt}_{60}$ & Skeleton & 74.3 & 52.3 & 1.0M EtOH & $1.0 \mathrm{M} \mathrm{NaOH}$ & 50 & 6.50 & 10.0 vs. $\mathrm{Pt} / \mathrm{C}$ & [114] \\
\hline $\mathrm{Ni}-\mathrm{Pd}_{60} \mathrm{Pt}_{40}$ & Skeleton & 75.4 & 54.3 & 1.0M EtOH & $1.0 \mathrm{M} \mathrm{NaOH}$ & 50 & 6.87 & 10.6 vs. $\mathrm{Pt} / \mathrm{C}$ & [114] \\
\hline PtAg & Skeleton & 24.7 & 19.4 & $\begin{array}{l}0.5 \mathrm{M} \text { Formic } \\
\text { acid }\end{array}$ & $0.1 \mathrm{M} \mathrm{HClO}_{4}$ & 50 & 0.4 & $\begin{array}{l}6.9 \text { vs. Pt } \\
\text { black }\end{array}$ & [41] \\
\hline Pd ${ }_{3} \mathrm{~Pb} @ \mathrm{Pd}$ & Skeleton & - & 41.8 & $\begin{array}{l}0.5 \mathrm{M} \text { Ethylene } \\
\text { glycol }\end{array}$ & $1 \mathrm{M} \mathrm{KOH}$ & 50 & 6.4 & $\begin{array}{l}5.8 \text { vs. Pd } \\
\text { black }\end{array}$ & [116] \\
\hline $\mathrm{Au}$ & Skeleton & 50.1 & 18.2 & 4mM Glucose & $0.1 \mathrm{M} \mathrm{NaOH}$ & 50 & 22 & - & [40] \\
\hline
\end{tabular}

Note: $\mathrm{MeOH}$ and EtOH refer to methanol and ethanol, respectively. ECSA refers to electrochemical surface area. BET surface areas are obatianed based on multipoint Brunauer-Emmett-Teller equation.

\subsubsection{Methanol oxidation reaction (MOR)}

As discussed in Section 3.1.2, carbon-based aerogels have been considered as a promising alternative support for improving the efficiency of nanoparticulate electrocatalysts. Pyrolysis of organic aerogels at high temperatures produces carbon aerogels with high surface area and conductivity. An ionic liquid has been utilized for the deposition of PtRu NPs on carbon aerogels, which prevents massive metal agglomeration and reaches an electrochemical surface area (ECSA) of $72 \mathrm{~m}^{2} \mathrm{~g}^{-1} \mathrm{Pt}^{[104]}$ Without the addition of cross-linking agents or surfactants, $\mathrm{Pt}$ NPs can be dispersed on graphene aerogel via a one-pot solvothermal process and achieve a mass activity 1.92-fold higher than the commercial Pt/C for MOR in acidic medium. ${ }^{[108]}$ Further modification of the graphene aerogel by nitrogen doping provided more anchoring sites forthe dispersion of Pt NPs, thus leading to an even higher Pt utilization efficiency (ECSA: $90.7 \mathrm{~m}^{2} \mathrm{~g}^{-}$ ${ }_{\mathrm{Pt}}$ ) and an improved mass activity (4.39-fold higher than Pt/C) for MOR. ${ }^{[105]}$

Meanwhile, carbon black supported Pt-based nanocatalysts can also be improved by integration with aerogels. For instance, encapsulation of the Pt/C catalysts into graphene aerogel leads to higher stability towards MOR in spite of a 5\% loss of the mass activity. ${ }^{[106]}$ Silica aerogel has been utilized to strengthen the carbon supported nanocatalysts via a Pt/C/silica composite 
aerogel. $^{[112]}$ The aerogel architecture locks in an electronic path through the carbon guest as well as a continuous, 3D mesoporous transport path for fuel molecules, solvent, and ions (Figure 3a,b). As a result, the electrocatalytic activity for MOR increases by 13-fold over the pristine $\mathrm{Pt} / \mathrm{C}$ catalyst.

Pure metallic aerogels with noble metals exposed on the surface have exhibited high activity and stability for MOR. Alloying Pt with Sn or Au has been employed to modify the electronic structure of Pt and introduce defects on the aerogel surface, thus achieving improved MOR activity in acidic medium. ${ }^{\left[107,{ }^{110]}\right.}$ In an alkaline medium, Pd-Ni alloy aerogels have revealed enhanced MOR activity due to the porous aerogel nature and a Ni alloying effect. ${ }^{[109]}$

\subsubsection{Ethanol oxidation reaction (EOR)}

Ethanol has a high energy density and can be acquired in large scale from renewable sources, thus being regarded as an ideal combustible for fuel cells. Moreover, its nontoxicity and ecological harmlessness also make it more appealing. The maximum utilization of the energy of ethanol relies on its complete oxidation to $\mathrm{CO}_{2}$, which requires the breaking of the C-C bond either in the ethanol or in the acetaldehyde intermediate. ${ }^{[117]}$ Most of the EOR electrocatalysts contain a high Pd or Pt content and lack of qualified stability. Pd-based aerogels haveemerged as a class of promising electrocatalyst for EOR in an alkaline environment. ${ }^{[2]}$ For example, metallic Pd aerogel synthesized via a "spontaneous" method exhibits an ECSA of $69 \mathrm{~m}^{2} \mathrm{~g}^{-1}$ and a 2.3-fold improvement in mass activity compared with $\mathrm{Pd} / \mathrm{C} .{ }^{[37]}$ Bimetallic $\mathrm{Pd}_{68} \mathrm{Cu}_{32}$ aerogel with an average diameter of $5.2 \mathrm{~nm}$ revealed an ECSA of $37.9 \mathrm{~m}^{2} \mathrm{~g}^{-1}$, and its mass activity reached $3.47 \mathrm{~A} \mathrm{mg}^{-1}$, which is nearly 3 times higher than that of the $\mathrm{Pd} / \mathrm{C}$ catalyst. $^{\text {[39] }}$

It has been demonstrated that hollow nanostructures are favorable for noble-metal catalysts. ${ }^{[118]}$ As shown in Figure 3c,d, hierarchical metallic aerogels composed of $\mathrm{Pd}_{\mathrm{x}} \mathrm{Ni}$ nanoshells were designed and exhibited an ECSA of $55.5 \mathrm{~m}^{2} \mathrm{~g}^{-1}$, highlighting the utilization efficiency of noble 
metals. ${ }^{[115]}$ By optimizing the composition and shell thickness, the $\mathrm{Pd}_{83} \mathrm{Ni}_{17}$ aerogel exhibited the highest mass and specific activities for EOR, which are 5.6- and 4.2-fold higher than the $\mathrm{Pd} / \mathrm{C}$ catalyst. To further tune the structure and catalytic performance, Pt was incorporated into the synthesis and a class of multimetallic $\mathrm{Ni}-\mathrm{Pd}_{\mathrm{x}} \mathrm{Pt}_{\mathrm{y}}$ hierarchical aerogels with porous or dendritic surfaces were fabricated. ${ }^{[114]}$ The hierarchical structure combines the nanoscaleregulated architecture and the macroscale 3D aerogel structure, leading to an abundance of exposed edges and a high surface area (varying from 95.4 to $67.7 \mathrm{~m}^{2} \mathrm{~g}^{-1}$ ). The electrocatalytic activity towards EOR on the Ni-Pd ${ }_{60} \mathrm{Pt}_{40}$ aerogel reaches 10.6- and 7.6-fold higher values than the $\mathrm{Pd} / \mathrm{C}$ and $\mathrm{Pt} / \mathrm{C}$, respectively.

\subsubsection{Other oxidation reactions}

Formic acid has been regarded as an alternative fuel due to its nontoxicity and higher theoretical open-circuit potential. The oxidation reaction of formic acid can produce $\mathrm{CO}_{2}$ via direct dehydrogenation or form a strongly adsorbed intermediate (i.e. CO) by dehydration. ${ }^{[119]}$ The latter process often occurs at pure Pt materials and thus poisons the Pt active sites. ${ }^{[120]}$ To tackle this issue, bimetallic PtAg tubular aerogel has been designed with the tuned electronic structure of Pt and hierarchical aerogel structure. ${ }^{[41]}$ This nanotubular PtAg aerogel exhibited a 19-fold mass activity compared to Pt black for formic acid electro-oxidation and showed an outstanding electrochemical and structural stability.

The use of ethylene glycol in direct alcohol fuel cells has also gained interests recently. Taking advantage of the aerogel structure, bimetallic PdPb-Pd aerogel has been synthesized under accelerated gelation kinetics. ${ }^{[116]}$ The surface enriched multiply-twinned grains of this aerogel lead to a 5.8 times higher mass activity versus Pd black towards ethylene glycol oxidation. Glucose oxidation is of great importance for sugar sensing in human blood and their potential 
use in fuel cells. Pure Au aerogels with diameters of 5-6 nm and high surface area were designed for the nonenzymatic oxidation of glucose. ${ }^{[40]}$

Incorporation of enzymes or microorganisms with porous aerogel catalysts facilitates electroenzymatic reactions thus benefiting biofuel cells. ${ }^{[121]}$ In this regard, the biofuel cell performance is related to the porosity of the aerogel catalysts, as the pores are required to accommodate the large biomolecules. ${ }^{[122]} \mathrm{A}$ positive correlation between the cell performance and pore size has been experimentally demonstrated on carbon aerogels for electrochemical oxidation of fructose. ${ }^{[123]}$ Improving ORR performance at a neutral $\mathrm{pH}$ is needed for efficient biofuel cells. Employing ORR-active nitrogen-doped carbon aerogel as air cathodes achieved a maximum power density which is 1.7 -fold higher than the commercial Pt/C cathodes. ${ }^{[124]}$ Metallic Pd-Pt aerogels have also been integrated with glucose oxidase for the construction of bio-anode, which realized the first membraneless glucose $/ \mathrm{O}_{2}$ biofuel cell with a maximum power output of $20 \mu \mathrm{W} \mathrm{cm}{ }^{-2}$ at $0.25 \mathrm{~V}^{[125]}$

\subsection{Water Splitting reactions}

The current large-scale hydrogen production relies on steam reforming of fossil fuels, which generates $\mathrm{CO}_{2}$ as impurities at the same time. Water electrolysis produces high purity hydrogen in an eco-friendly way following two half-cell reactions: the hydrogen evolution reaction (HER; $2 \mathrm{H}^{+}(\mathrm{aq})+2 \mathrm{e}^{-} \rightarrow \mathrm{H}_{2}(\mathrm{~g})$ ), and the oxygen evolution reaction $\left(\mathrm{OER} ; 2 \mathrm{H}_{2} \mathrm{O}(\mathrm{l}) \rightarrow \mathrm{O}_{2}(\mathrm{~g})+4 \mathrm{H}^{+}(\mathrm{aq})\right.$ $\left.+4 \mathrm{e}^{-}\right)$. Highly active and low-cost electrocatalysts with low overpotentials for HER and OER are imperative.

\subsubsection{Hydrogen evolution}


Since the HER is a two-electron transfer reaction with one catalytic intermediate (i.e. $\mathrm{H}^{*}$ ), its reaction rate is largely determined by the hydrogen adsorption free energy, $\Delta \mathrm{G}_{\mathrm{H} .}{ }^{[126]}$ An ideal catalyst binds the reaction intermediate neither too strongly nor too weakly. In addition to the precious Pt materials, group VIII 3d metal sulfide, selenide, and phosphide nanomaterials have risen as abundant catalyst materials for HER. ${ }^{[127]}$

Table 4. Overview of the HER performances of different aerogel electrocatalysts obtained from three-electrode setups. Overpotentials are derived from the potentials at $10 \mathrm{~mA} \mathrm{~cm}{ }_{\text {geo }}\left(\eta^{10}\right)$. Since the current density normalized by the geometrical area does not reflect the intrinsic activity of the catalysts, the surface area of the catalysts and their loading should be taken into account during the evaluation of the overpotentials.

\begin{tabular}{|c|c|c|c|c|c|c|c|}
\hline Aerogel materials & $\begin{array}{c}\text { Surface area } \\
\left(\mathrm{m}^{2} \mathrm{~g}^{-1}\right)\end{array}$ & Electrolyte & $\begin{array}{l}\text { Catalyst loading } \\
\text { (ug } \mathrm{cm}^{-2} \text { ) }\end{array}$ & $\begin{array}{l}\text { Scan rate } \\
\left(\mathrm{mV} \mathrm{s}^{-1}\right)\end{array}$ & $\begin{array}{l}\text { Overpotential } \\
(\mathrm{mV})\end{array}$ & $\begin{array}{l}\text { Tafel slope } \\
\left(\mathrm{mV} \text { dec }^{-1}\right)\end{array}$ & ref \\
\hline Co-N-graphene & 466.6 & $0.5 \mathrm{M} \mathrm{H}_{2} \mathrm{SO}_{4}$ & 275 & 5 & 50 & 33 & [79] \\
\hline $\mathrm{Ni}_{3} \mathrm{FeN} /$ graphene & 171 & $1.0 \mathrm{M} \mathrm{KOH}$ & 500 & 5 & 94 & 90 & [128] \\
\hline $\mathrm{MoS}_{2}$ /graphene & 700 & $0.5 \mathrm{M} \mathrm{H}_{2} \mathrm{SO}_{4}$ & 2000 & 2 & 120 & - & [129] \\
\hline CoP-C/graphene & 31.4 & $0.5 \mathrm{M} \mathrm{H}_{2} \mathrm{SO}_{4}$ & 280 & 5 & 120 & 57 & [130] \\
\hline $\mathrm{WSe}_{2} / \mathrm{NiFe}-\mathrm{LDH} / \mathrm{N}, \mathrm{S}$-graphene & 110 & $1.0 \mathrm{M} \mathrm{KOH}$ & 1000 & 2 & 122 & 112 & [131] \\
\hline (Ni,Co)Se $e_{2}$ graphene & 123.0 & $1.0 \mathrm{M} \mathrm{KOH}$ & 2650 & 1 & 128 & 79 & [132] \\
\hline CoP/graphene & 532.2 & $0.5 \mathrm{M} \mathrm{H}_{2} \mathrm{SO}_{4}$ & 280 & 2 & 121 & 61 & [133] \\
\hline Ru/N-graphene & 244.8 & $0.1 \mathrm{M} \mathrm{KOH}$ & 100 & 5 & 145 & 109 & [134] \\
\hline $\mathrm{MoS}_{2}$ /graphene & 294 & $0.5 \mathrm{M} \mathrm{H}_{2} \mathrm{SO}_{4}$ & - & 5 & 162 & 41 & [135] \\
\hline $\mathrm{MoS}_{2} / \mathrm{N}$-graphene & - & $0.5 \mathrm{M} \mathrm{H}_{2} \mathrm{SO}_{4}$ & 327 & 2 & 170 & 53 & [136] \\
\hline $\mathrm{MoSe}_{2} /$ carbon-fiber & 62 & $0.5 \mathrm{M} \mathrm{H}_{2} \mathrm{SO}_{4}$ & - & 2 & 175 & 62 & [137] \\
\hline O-MoS 2 /graphene & - & $0.5 \mathrm{M} \mathrm{H}_{2} \mathrm{SO}_{4}$ & 130 & 100 & 187 & 40 & [138] \\
\hline $\mathrm{MoS}_{\mathrm{x}} / \mathrm{CNT}$ & - & $0.5 \mathrm{M} \mathrm{H}_{2} \mathrm{SO}_{4}$ & 357 & 2 & 210 & 62 & [139] \\
\hline $\mathrm{MoSe}_{2} / \mathrm{CNT}$ /graphene & - & $0.5 \mathrm{M} \mathrm{H}_{2} \mathrm{SO}_{4}$ & - & 2 & 225 & 68 & [140] \\
\hline CoP-C/graphene & 31.4 & $1.0 \mathrm{M} \mathrm{KOH}$ & 280 & 5 & 225 & 66 & [130] \\
\hline $\mathrm{Ni}_{2} \mathrm{P}$-C/graphene & - & $0.5 \mathrm{M} \mathrm{H}_{2} \mathrm{SO}_{4}$ & 280 & 5 & 310 & 74 & [130] \\
\hline $\mathrm{Ni}_{2} \mathrm{P}$-C/graphene & - & $1.0 \mathrm{M} \mathrm{KOH}$ & 280 & 5 & 340 & 97 & [130] \\
\hline
\end{tabular}

The HER activity of $\mathrm{MoS}_{2}$ strongly depends on its catalytically active exposed edges. ${ }^{[141]}$ The incorporation of $\mathrm{MoS}_{2}$ with carbon-based aerogels offers several advantages, such as a high surface-to-volume ratio, good stability under harsh conditions, and fast current collection. Wu et al. synthesized oxygen doped $\mathrm{MoS}_{2}$ /graphene composite aerogels with $\mathrm{MoS}_{2}$ vertically aligned edges decorated on the aerogel skeleton. ${ }^{[138]}$ The as-prepared O-MoS 2 /graphene aerogel suppressed the aggregation of $\mathrm{MoS}_{2}$ nanosheets and showed a Tafel slope as low as $40 \mathrm{mV}$ per decade and an overpotential of $187 \mathrm{mV}$. The sufficient exposure of $\mathrm{MoS}_{2}$ active edges canalso be achieved on CNT aerogel frameworks, where the conducting skeleton provides fast charge transport. ${ }^{[139]}$ In acidic medium, the $\mathrm{MoS}_{2} / \mathrm{CNT}$ aerogel exhibited an overpotential of $210 \mathrm{mV}$ 
and negligible degradation after 1000 cycles. Nitrogen doping of the graphene aerogel substrate has shown further improvement on the composite catalyst for HER. ${ }^{[136]}$

Instead of anchoring sulfide nanosheets in aerogels, $(\mathrm{Ni}, \mathrm{Co}) \mathrm{Se}_{2}$ nanocages has been decorated on graphene aerogel skeletons (Figure 4a-c) ${ }^{[132]}$ The morphology of nanocages provides more exposed active sites during the HER on $\mathrm{Ni}$ foam in an alkaline medium. The resultant composite catalyst only needs an overpotential of $128 \mathrm{mV}$ to achieve a current density of $10 \mathrm{~mA} \mathrm{~cm}$. Cobalt phosphide NPs have been encapsulated uniformly within graphene aerogels by phosphorization of a Co/graphene aerogel. ${ }^{[133]}$ When used as HER catalyst, the CoP/graphene aerogel showed an onset potential of $121 \mathrm{mV}$, a Tafel slope of $50 \mathrm{mV} \mathrm{dec}{ }^{-1}$, and a large exchange current density of $0.105 \mathrm{~mA} \mathrm{~cm}^{-2}$. Encapsulation of the metal phosphide NPs with a carbon shell before decoration in aerogels can further improve the electrochemical stability. The CoP-C/graphene aerogel exhibited a stable cathodic current (at $10 \mathrm{~mA} \mathrm{~cm}^{-2}$ ) over $12000 \mathrm{~s}$ and negligible degradation after 1000 cycles. ${ }^{[130]}$

\subsubsection{Oxygen evolution}

To date, the most effective catalysts for the sluggish OER are still based on noble metals, i.e. Ru- and Ir-based materials. As replacements, the transition metal oxide, sulfide, selenide, and phosphide nanomaterials have shown their efficiency for OER, although the real active species are the situ formed surface (oxy)hydroxides. ${ }^{[142]}$ Due to the low electrical conductivities of these materials, the incorporation of them into 3D conducting scaffolds showes enormous potential. For instance, a ternary hybrid aerogel assembled from WSe 2 nanosheets, NiFe-LDH nanosheets, and N,S-codoped graphene has been fabricated via a hydrothermal method. ${ }^{[131]}$ Serving as an OER catalyst, the obtained composite aerogel requires an overpotential of $250 \mathrm{mV}$ to reach a current density of $10 \mathrm{~mA} \mathrm{~cm}^{-2}$ in alkaline solution. The aforementioned (Ni,Co)Se $/$ graphene 
aerogel (c.f. Section 3.3.1) also exhibit excellent OER activities, thus leading to a cell voltage of $1.60 \mathrm{~V}$ to reach a current density of $10 \mathrm{~mA} \mathrm{~cm}{ }^{-2}$ for the overall water splitting. ${ }^{\text {[132] }}$

Using (Co,Ni) $\mathrm{S}_{2} / \mathrm{N}$-graphene aerogel as a prototype, the charge transfer mechanism between sulfide and graphene has been revealed (Figure 4d-f). ${ }^{[143]}$ Cobalt atoms anchored on pyridinic $\mathrm{N}$ sites in the graphene aerogel support form metal-semiconductor junctions, and the internal band bending at these junctions facilitate electron transfer from sulfides to graphene. During catalyzing the OER, partially oxidized amorphous metal sulfide layers formed can facilitate the adsorption and desorption of $\mathrm{OH}$ and $\mathrm{H}$ atoms, thus lowering the overpotential to $330 \mathrm{mV}$ at 10 $\mathrm{mA} \mathrm{cm}{ }^{-2}$ and a Tafel slope of $47 \mathrm{mV} \mathrm{dec}^{-1}$ in alkaline solution.

In addition to the composite aerogels, metal oxide aerogels composed of active species are promising OER catalysts. Single-phase $\mathrm{NiFe}_{2} \mathrm{O}_{x}$ aerogel with an increased surface area and pore volume have been synthesized via a sol-gel process. ${ }^{[144]}$ Calcination at $300^{\circ} \mathrm{Cin}$ argon decreases the surface area from 477 to $198 \mathrm{~m}^{2} \mathrm{~g}^{-1}$. However, the crystallization into the spinel structure enabled an efficient OER catalysis with an overpotential of $356 \mathrm{mV}$ at $10 \mathrm{~mA} \mathrm{~cm}{ }^{-2}$ when the catalyst loading is only $40 \mu \mathrm{g} \mathrm{cm}$. . On the other hand, FeCoW oxy-hydroxide aerogel reveals a better OER performance before calcination. ${ }^{[18]}$ Specifically, it exhibits the lowest overpotential of $191 \mathrm{mV}$ at $10 \mathrm{~mA} \mathrm{~cm}$ ch $^{-2}$ in alkaline solution and shows no evidence of degradation following more than 500 hours of operation. A synergistic interplay between $\mathrm{W}$, Fe, and Co in producing a favorable local coordination environment and electronic structure makes the main contribution to the improved OER activity, which could be interfered with after calcination or crystallization.

Table 5. Overview of the OER performances of different aerogel electrocatalysts obtained from three-electrode setups. Overpotentials are derived from the potential at $10 \mathrm{~mA} \mathrm{~cm}^{-2}$ geo $\left(\eta^{10}\right)$. Since the current density normalized by the geometrical area does not reflect the intrinsic activity of the catalysts, the surface area of the catalysts and their loading should be taken in to account during the evaluation of the overpotentials. 


\begin{tabular}{|c|c|c|c|c|c|c|c|}
\hline Aerogel materials & $\begin{array}{c}\mathrm{BET} \\
\left(\mathrm{m}^{2} \mathrm{~g}^{-1}\right)\end{array}$ & Electrolyte & $\begin{array}{l}\text { Catalyst loading } \\
\text { (ug } \mathrm{cm}^{-2} \text { ) }\end{array}$ & $\begin{array}{l}\text { Scan rate } \\
\left(\mathrm{mV} \mathrm{s}^{-1}\right)\end{array}$ & $\begin{array}{l}\text { Overotential } \\
(\mathrm{mV})\end{array}$ & $\begin{array}{l}\text { Tafel slope } \\
\left(\mathrm{mV} \operatorname{dec}^{-1}\right)\end{array}$ & ref \\
\hline FeCoW oxide & 29.8 & $1.0 \mathrm{M} \mathrm{KOH}$ & 210 & 1 & 223 & 37 & [18] \\
\hline $\mathrm{WSe}_{2} / \mathrm{NiFe}-\mathrm{LDH} / \mathrm{N}$,S-graphene & 110 & $1.0 \mathrm{M} \mathrm{KOH}$ & 1000 & 2 & 250 & 86 & [131] \\
\hline $\mathrm{Ni}_{3} \mathrm{FeN} /$ graphene & 171 & $1.0 \mathrm{M} \mathrm{KOH}$ & 500 & 5 & 270 & 54 & [128] \\
\hline FeCo oxide & 47.8 & $1.0 \mathrm{M} \mathrm{KOH}$ & 210 & 1 & 277 & 60 & [18] \\
\hline CoW oxide & - & $1.0 \mathrm{M} \mathrm{KOH}$ & 210 & 1 & 300 & 55 & [18] \\
\hline $\mathrm{IrO}_{\mathrm{x}} / \mathrm{Sb}-\mathrm{SnO}_{2}$ & - & $0.5 \mathrm{M} \mathrm{H}_{2} \mathrm{SO}_{4}$ & 60 & 5 & 310 & 40.9 & [145] \\
\hline$(\mathrm{Co}, \mathrm{Ni}) \mathrm{S}_{2} / \mathrm{N}$-graphene & 99.1 & $1.0 \mathrm{M} \mathrm{KOH}$ & 285 & 0.5 & 330 & 47 & [143] \\
\hline $\mathrm{Co}_{9} \mathrm{~S}_{8} / \mathrm{N}, \mathrm{S}, \mathrm{P}$-graphene & 478 & $0.1 \mathrm{M} \mathrm{KOH}$ & 283 & 10 & 343 & 82 & [81] \\
\hline $\mathrm{NiFe}_{2} \mathrm{O}_{x}$ & 198 & $1.0 \mathrm{M} \mathrm{KOH}$ & 40 & 10 & 356 & 57 & [144] \\
\hline (Ni,Co)Se $\mathrm{Se}_{2}$ graphene & 123.0 & $1.0 \mathrm{M} \mathrm{KOH}$ & 2650 & 1 & 370 & 70 & [132] \\
\hline $\mathrm{Ni} / \mathrm{MnO} /$ graphene & 109 & $0.1 \mathrm{M} \mathrm{KOH}$ & 250 & 5 & 370 & 67 & [88] \\
\hline Ru/N-graphene & 244.8 & $0.1 \mathrm{M} \mathrm{KOH}$ & 100 & 20 & 390 & - & [134] \\
\hline
\end{tabular}

\section{Conclusions and Perspectives}

Recent years have witnessed a growing interest in the development of advanced electrocatalysts for clean energy conversion and storage. Combining the catalytically active species into the design and synthesis of aerogels leads to the emerging of a series of aerogel-based electrocatalysts, including heteroatom-doped nanocarbon aerogels, carbon-based composite aerogels, metal oxide aerogels and pure metallic aerogels. The versatile sol-gel synthesis was demonstrated by dividing into several synthetic steps. Their application in four representative electrocatalysis reactions related to fuel cells and water electrolysis, i.e. ORR, fuel oxidation, HER, and OER, were reviewed by organizing and comparing the activities of different aerogels. In general, the large surface area, high porosity, conductive 3D skeleton, and self-supportability of these aerogel catalysts contribute synergistically to the improved electrocatalytic performance.

In spite of the continuous progress that has led to the design and synthesis of advanced aerogel catalysts, there still remain many problems that need to be addressed. Firstly, the heteroatomdoped nanocarbon aerogels have shown astonishing ORR performance based on rotation disk electrode measurements (mostly in alkaline solutions). However, the loading of the catalysts has to be high enough to achieve a lower overpotential and high current density at a certain potential. This apparently results in a low specific activity and mass activity of those catalysts 
when normalizing to the specific surface area and catalyst mass. Considering the low density of these aerogels, moreover, it will lead to a large thickness of the catalyst layer in a fuel cell stack, which often causes a high potential drop. Therefore, future research should focus on how to take full advantage of the high surface area (i.e. active sites) in electrocatalysis and further translate the high activity into fuel cell tests. The single-atom catalysts which often use graphene as a substrate would be a promising direction to further improve the intrinsic activity of graphene-based aerogels.

Secondly, active species/nanocarbon composite aerogels usually possess improved stability in both alkaline and acid solutions due to the robustness of graphene or CNTs. Increasing the loading of active species without causing agglomeration would increase the utilization efficiency of carbon aerogels, thus leading to a thinner catalyst film and facilitating the exposure of active species to reactants. Appropriate heteroatom doping can not only tune the electronic structure of carbon aerogel supports but also induce a synergistic effect between the support and active species (e.g. metal nitrides, sulfides, phosphides).

Thirdly, transition metal oxides/oxy-hydroxides have shown their potential application in electrocatalysis and their aerogel counterparts can be facilely synthesized through an epoxidemediated gelation process. However, studies on their electrocatalytic properties remain largely unexplored. Post-treatment of the multi-metal oxide aerogels can crystallize them into spinel or perovskite structures, which shows the potential applications in high-temperature solid oxide fuel cells (500-1000 $\left.{ }^{\circ} \mathrm{C}\right)$. M etal sulfites and phosphides which are potential HER/OERcatalysts would be promising materials for fabricating aerogel electrocatalysts.

Finally, transferring the achievements in fine-tuned nanoparticulate catalysts into the design of hierarchical metallic aerogels remains an important and challenging pursuit for designing application-oriented electrocatalysts. Recently, transition metal alloying (e.g. Pd-Ni, Pt-Ni, PtAg, Pt-Cu) and shape/structure tuning (e.g. hollow, dendritic, porous, core-shell) effects have 
been realized in the design of metallic aerogel catalysts that showed improved activity for both ORR and alcohol oxidation. However, these hierarchical structures are limited to several specific compositions and need to be expanded to other systems. Recently, facet engineering has been realized in Au-containing aerogels by size-dependent localized Ostwald ripening in order to further improve the electrocatalytic performance, which hold tremendous potential for metallic aerogels with other elements. ${ }^{[146]}$ Moreover, many other nano-engineering strategies, such as near-surface composition and Janus structures, still remain challenging for the design of metallic aerogel catalysts. To facilitate the commercialization of aerogel catalysts, novel synthesis strategies towards a low-cost and large-scale production are highly needed.

\section{Acknowledgments}

Financial support from the European Research Council (ERC-2013-AdG AEROCAT) is gratefully appreciated.

Received: ((will be filled in by the editorial staff))

Revised: ((will be filled in by the editorial staff)) Published online: ((will be filled in by the editorial staff))

\section{References}

[1] Z. W. Seh, J. Kibsgaard, C. F. Dickens, I. Chorkendorff, J. K. Norskov, T. F. Jaramillo, Science 2017, 355, eaad4998.

[2] C. Zhu, D. Du, A. Eychmüller, Y. Lin, Chem. Rev. 2015, 115, 8896.

[3] N. Hüsing, U. Schubert, Angew. Chem. Int. Ed. 1998, 37, 22.

[4] S. Zhao, W. J. Malfait, N. Guerrero-Alburquerque, M. M. Koebel, G. Nystrom, Angew. Chem. Int. Ed. 2018, DOI: 10.1002/anie.201709014.

[5] A. C. Pierre, G. M. Pajonk, Chem. Rev. 2002, 102, 4243.

[6] C. Ziegler, A. Wolf, W. Liu, A. K. Herrmann, N. Gaponik, A. Eychmüller, Angew. Chem. Int. Ed. 2017, 56, 13200.

[7] A. Soleimani Dorcheh, M. H. Abbasi, J. Mater. Proc. Tech. 2008, 199, 10.

[8] C. Moreno-Castilla, F. J. Maldonado-Hodar, Carbon 2005, 43, 455.

[9] H. Hu, Z. Zhao, W. Wan, Y. Gogotsi, J. Qiu, Adv. Mater. 2013, 25, 2219.

[10] M. B. Bryning, D. E. Milkie, M. F. Islam, L. A. Hough, J. M. Kikkawa, A. G. Yodh, Adv. Mater. 2007, 19, 661.

[11] Z. S. Wu, S. Yang, Y. Sun, K. Parvez, X. Feng, K. Mullen, J. Am. Chem. Soc. 2012, 134, 9082.

[12] J. L. Mohanan, I. U. Arachchige, S. L. Brock, Science 2005, 307, 397.

[13] D. Wang, Y. Li, Adv. Mater. 2011, 23, 1044. 
[14] X. Xia, Y. Wang, A. Ruditskiy, Y. Xia, Adv. Mater. 2013, 25, 6313.

[15] S. Guo, S. Zhang, S. Sun, Angew. Chem. Int. Ed. 2013, 52, 8526.

[16] W. Liu, A. K. Herrmann, N. C. Bigall, P. Rodriguez, D. Wen, M. Oezaslan, T. J. Schmidt, N. Gaponik, A. Eychmüller, Acc. Chem. Res. 2015, 48, 154.

[17] B. Cai, S. Henning, J. Herranz, T. J. Schmidt, A. Eychmüller, Adv. Energy Mater. 2017, 7, 1700548.

[18] B. Zhang, X. Zheng, O. Voznyy, R. Comin, M. Bajdich, M. Garcia-Melchor, L. Han, J. Xu, M. Liu, L. Zheng, F. P. Garcia de Arquer, C. T. Dinh, F. Fan, M. Yuan, E.

Yassitepe, N. Chen, T. Regier, P. Liu, Y. Li, P. De Luna, A. Janmohamed, H. L. Xin, H. Yang, A. Vojvodic, E. H. Sargent, Science 2016, 352, 333.

[19] J. M. Christ, C. Ngo, T. Batson, C. A. Cadigan, J. Tong, R. M. Richards, R. O'Hayre, S. Pylypenko, Catal. Sci. Technol. 2016, 6, 7744.

[20] S. Mulik, C. Sotiriou-Leventis, in Aerogels Handbook, (Eds: M. A. Aegerter, N. Leventis, M. M. Koebel), Springer New York, New York, NY 2011, 215.

[21] H. Tamon, H. Ishizaka, T. Yamamoto, T. Suzuki, Carbon 1999, 37, 2049.

[22] Y. Xu, K. Sheng, C. Li, G. Shi, ACS Nano 2010, 4, 4324.

[23] W. Chen, L. Yan, Nanoscale 2011, 3, 3132.

[24] J. J. Mao, J. Iocozzia, J. Y. Huang, K. Meng, Y. K. Lai, Z. Q. Lin, Energy Environ. Sci. 2018, 11, 772.

[25] L. Qiu, J. Z. Liu, S. L. Chang, Y. Wu, D. Li, Nat. Comm. 2012, 3, 1241.

[26] B. Zhang, J. Zhang, X. Sang, C. Liu, T. Luo, L. Peng, B. Han, X. Tan, X. Ma, D. Wang, N. Zhao, Sci. Rep. 2016, 6, 25830.

[27] Z.-X. Cai, X.-H. Song, Y.-Y. Chen, Y.-R. Wang, X. Chen, Sensors and Actuators B: Chemical 2016, 222, 567.

[28] Q. Wang, Z. Chen, N. Wu, B. Wang, W. He, Y. Lei, Y. Wang, ChemElectroChem 2017, 4, 514.

[29] X. Fu, J. Y. Choi, P. Zamani, G. Jiang, M. A. Hoque, F. M. Hassan, Z. Chen, ACS Appl. Mater. Interfaces 2016, 8, 6488.

[30] A. Sarapuu, L. Samolberg, K. Kreek, M. Koel, L. Matisen, K. Tammeveski, J. Electroanal. Chem. 2015, 746, 9.

[31] B. Cai, V. Sayevich, N. Gaponik, A. Eychmüller, Adv. Mater. 2018, 1707518.

[32] A. K. Herrmann, P. Formanek, L. Borchardt, M. Klose, L. Giebeler, J. Eckert, S. Kaskel, N. Gaponik, A. Eychmüller, Chem. Mater. 2014, 26, 1074.

[33] D. Wen, A. K. Herrmann, L. Borchardt, F. Simon, W. Liu, S. Kaskel, A. Eychmüller, J. Am. Chem. Soc. 2014, 136, 2727.

[34] N. C. Bigall, A. K. Herrmann, M. Vogel, M. Rose, P. Simon, W. Carrillo-Cabrera, D. Dorfs, S. Kaskel, N. Gaponik, A. Eychmüller, Angew. Chem. Int. Ed. 2009, 48, 9731.

[35] K. G. S. Ranmohotti, X. N. Gao, I. U. Arachchige, Chem. Mater. 2013, 25, 3528.

[36] X. Gao, R. J. Esteves, T. T. Luong, R. Jaini, I. U. Arachchige, J. Am. Chem. Soc. 2014, 136, 7993.

[37] W. Liu, A. K. Herrmann, D. Geiger, L. Borchardt, F. Simon, S. Kaskel, N. Gaponik, A. Eychmüller, Angew. Chem. Int. Ed. 2012, 51, 5743.

[38] W. Liu, P. Rodriguez, L. Borchardt, A. Foelske, J. Yuan, A. K. Herrmann, D. Geiger, Z. Zheng, S. Kaskel, N. Gaponik, R. Kotz, T. J. Schmidt, A. Eychmüller, Angew. Chem. Int. Ed. 2013, 52, 9849.

[39] C. Zhu, Q. Shi, S. Fu, J. Song, H. Xia, D. Du, Y. Lin, Adv. Mater. 2016, 28, 8779.

[40] D. Wen, W. Liu, D. Haubold, C. Zhu, M. Oschatz, M. Holzschuh, A. Wolf, F. Simon, S. Kaskel, A. Eychmüller, ACS Nano 2016, 10, 2559.

[41] W. Liu, D. Haubold, B. Rutkowski, M. Oschatz, R. Hübner, M. Werheid, C. Ziegler, L. Sonntag, S. H. Liu, Z. K. Zheng, A. K. Herrmann, D. Geiger, B. Terlan, T. 
Gemming, L. Borchardt, S. Kaskel, A. Czyrska-Filemonowicz, A. Eychmüller, Chem. Mater. 2016, 28, 6477.

[42] B. Cai, R. Hübner, K. Sasaki, Y. Zhang, D. Su, C. Ziegler, M. B. Vukmirovic, B. Rellinghaus, R. R. Adzic, A. Eychmüller, Angew. Chem. Int. Ed. 2018, 57, 2963.

[43] P. Lv, X. Tang, W. Wei, RSC Adv. 2017, 7, 47116.

[44] Y. Xue, J. Liu, H. Chen, R. Wang, D. Li, J. Qu, L. Dai, Angew. Chem. Int. Ed. 2012, 51, 12124.

[45] A. Freytag, S. Sanchez-Paradinas, S. Naskar, N. Wendt, M. Colombo, G. Pugliese, J. Poppe, C. Demirci, I. Kretschmer, D. W. Bahnemann, P. Behrens, N. C. Bigall, Angew. Chem. Int. Ed. 2016, 55, 1200.

[46] T. Mittermeier, A. Weiß, F. Hasché, G. Hübner, H. A. Gasteiger, J. Electrochem. Soc 2016, 164, F127.

[47] B. Qiu, M. Xing, J. Zhang, Chem. Soc. Rev. 2018, 47, 2165.

[48] Y. J. Kang, P. D. Yang, N. M. Markovic, V. R. Stamenkovic, Nano Today 2016, 11, 587.

[49] H. Mistry, A. S. Varela, S. Kuhl, P. Strasser, B. R. Cuenya, Nat Rev Mater 2016, 1, 16009.

[50] T. Y. Ma, S. Dai, S. Z. Qiao, Mater. Today 2016, 19, 265.

[51] J. Speder, A. Zana, I. Spanos, J. J. K. Kirkensgaard, K. Mortensen, M. Hanzlik, M. Arenz, J. Power Sources 2014, 261, 14.

[52] Y. Ding, Y. J. Kim, J. Erlebacher, Adv. Mater. 2004, 16, 1897.

[53] C. X. Xu, L. Q. Wang, R. Y. Wang, K. Wang, Y. Zhang, F. Tian, Y. Ding, Adv. Mater. 2009, 21, 2165.

[54] R. Y. Wang, C. X. Xu, X. X. Bi, Y. Ding, Energy Environ. Sci. 2012, 5, 5281.

[55] Y. Ding, J. Erlebacher, J. Am. Chem. Soc. 2003, 125, 7772.

[56] M. Shao, Q. Chang, J. P. Dodelet, R. Chenitz, Chem. Rev. 2016, 116, 3594.

[57] L. Dai, Y. Xue, L. Qu, H. J. Choi, J. B. Baek, Chem. Rev. 2015, 115, 4823.

[58] G. Wu, P. Zelenay, Acc Chem Res 2013, 46, 1878.

[59] C. Zhu, H. Li, S. Fu, D. Du, Y. Lin, Chem. Soc. Rev. 2016, 45, 517.

[60] K. Gong, F. Du, Z. Xia, M. Durstock, L. Dai, Science 2009, 323, 760.

[61] L. Yang, S. Jiang, Y. Zhao, L. Zhu, S. Chen, X. Wang, Q. Wu, J. Ma, Y. Ma, Z. Hu, Angew. Chem. Int. Ed. 2011, 50, 7132.

[62] C. Xu, Y. Su, D. Liu, X. He, Physical chemistry chemical physics : PCCP 2015, 17, 25440.

[63] S. F. Fu, C. Z. Zhu, J. H. Song, M. H. Engelhard, B. W. Xiao, D. Du, Y. H. Lin, Chem Eur J 2017, 23, 10460.

[64] C. Zhu, S. Fu, J. Song, Q. Shi, D. Su, M. H. Engelhard, X. Li, D. Xiao, D. Li, L. Estevez, D. Du, Y. Lin, Small 2017, 13.

[65] J. Zhang, Z. Zhao, Z. Xia, L. Dai, Nat Nanotechnol 2015, 10, 444.

[66] M. Seredych, K. László, T. J. Bandosz, ChemCatChem 2015, 7, 2924.

[67] M. Wang, J. Wang, Y. Hou, D. Shi, D. Wexler, S. D. Poynton, R. C. Slade, W. Zhang, H. Liu, J. Chen, ACS Appl. Mater. Interfaces 2015, 7, 7066.

[68] C. Li, F. Sun, Y. Lin, J. Power Sources 2018, 384, 48.

[69] T. Palaniselvam, V. Kashyap, S. N. Bhange, J. B. Baek, S. Kurungot, Adv. Funct. Mater. 2016, 26, 2150.

[70] W. Q. Kong, K. K. Yao, X. D. Duan, Z. G. Liu, J. W. Hu, Electrochim. Acta 2018, 269, 544.

[71] Y. Wang, H. Liu, K. Wang, S. Song, P. Tsiakaras, Appl. Catal. B: Environ. 2017, 210, 57.

[72] H.-W. Liang, Z.-Y. Wu, L.-F. Chen, C. Li, S.-H. Yu, Nano Energy 2015, 11, 366. 
[73] L. Chen, C. Y. Xu, R. Du, Y. Y. Mao, C. Xue, L. M. Chen, L. T. Qu, J. Zhang, T. Yi, J Mater Chem A 2015, 3, 5617.

[74] Y. B. Li, H. M. Zhang, P. R. Liu, Y. Wang, H. G. Yang, Y. Li, H. J. Zhao, Electrochem Commun 2015, 51, 6.

[75] P. Kolla, C. Lai, S. Mishra, H. Fong, W. Rhine, A. Smirnova, Carbon 2014, 79, 518.

[76] S. Hu, T. Han, C. Lin, W. K. Xiang, Y. H. Zhao, P. Gao, F. P. Du, X. P. Li, Y. H. Sun, Adv. Funct. Mater. 2017, 27, 1700041.

[77] G. He, M. Qiao, W. Li, Y. Lu, T. Zhao, R. Zou, B. Li, J. A. Darr, J. Hu, M. M. Titirici, I. P. Parkin, Adv Sci 2017, 4, 1600214.

[78] Z. Xu, Y. Zhang, Y. Wang, L. Zhan, Appl. Surf. Sci. 2018, 450, 348.

[79] Z. Zhu, Y. Yang, Y. Guan, J. Xue, L. Cui, J Mater Chem A 2016, 4, 15536.

[80] S. Zeng, H. Chen, H. Wang, X. Tong, M. Chen, J. Di, Q. Li, Small 2017, 13.

[81] X. X. Ma, X. H. Dai, X. Q. He, Acs Sustain Chem Eng 2017, 5, 9848.

[82] Z. Luo, C. Tan, X. Zhang, J. Chen, X. Cao, B. Li, Y. Zong, L. Huang, X. Huang, L. Wang, W. Huang, H. Zhang, Small 2016, 12, 5920.

[83] W. H. Guo, X. X. Ma, X. L. Zhang, Y. Q. Zhang, D. L. Yu, X. Q. He, RSC Adv. 2016, 6, 96436.

[84] Y. Liu, H. Wang, D. Lin, J. Zhao, C. Liu, J. Xie, Y. Cui, Nano Res. 2016, 10, 1213.

[85] Z. Liang, W. Xia, C. Qu, B. Qiu, H. Tabassum, S. Gao, R. Zou, ChemElectroChem 2017, 4, 2442.

[86] W. Xia, C. Qu, Z. Liang, B. Zhao, S. Dai, B. Qiu, Y. Jiao, Q. Zhang, X. Huang, W. Guo, D. Dang, R. Zou, D. Xia, Q. Xu, M. Liu, Nano Lett. 2017, 17, 2788.

[87] H. Yin, C. Z. Zhang, F. Liu, Y. L. Hou, Adv. Funct. Mater. 2014, 24, 2930.

[88] G. Fu, X. Yan, Y. Chen, L. Xu, D. Sun, J. M. Lee, Y. Tang, Adv. Mater. 2018, 30, 1704609.

[89] F. E. Sarac Oztuna, S. B. Barim, S. E. Bozbag, H. Yu, M. Aindow, U. Unal, C. Erkey, Electrochim. Acta 2017, 250, 174.

[90] Q. H. Huang, F. F. Tao, L. L. Zou, T. Yuan, Z. Q. Zou, H. F. Zhang, X. G. Zhang, H. Yang, Electrochim. Acta 2015, 152, 140.

[91] P. Kolla, A. Smirnova, Electrochim Acta 2015, 182, 20.

[92] G. Ozouf, G. Cognard, F. Maillard, M. Chatenet, L. Guétaz, M. Heitzmann, P. A. Jacques, C. Beauger, J. Electrochem. Soc. 2018, 165, F3036.

[93] Q. R. Shi, C. Z. Zhu, Y. J. Li, H. B. Xia, M. H. Engelhard, S. F. Fu, D. Du, Y. H. Lin, Chem. Mater. 2016, 28, 7928.

[94] G. Cognard, G. Ozouf, C. Beauger, L. Dubau, M. Lopez-Haro, M. Chatenet, F. Maillard, Electrochim. Acta 2017, 245, 993.

[95] G. Cognard, G. Ozouf, C. Beauger, G. Berthomé, D. Riassetto, L. Dubau, R. Chattot, M. Chatenet, F. Maillard, Appl. Catal. B: Environ. 2017, 201, 381.

[96] S. Henning, L. Kühn, J. Herranz, J. Durst, T. Binninger, M. Nachtegaal, M. Werheid, W. Liu, M. Adam, S. Kaskel, A. Eychmüller, T. J. Schmidt, J. Electrochem. Soc. 2016, 163, F998.

[97] B. B. Xie, Y. Zhang, R. J. Zhang, J Mater Chem A 2017, 5, 17544.

[98] S. B. Barim, S. E. Bozbag, H. Yu, R. Kızılel, M. Aindow, C. Erkey, Catal. Today 2018, 310, 166.

[99] S. Guo, S. Sun, J. Am. Chem. Soc. 2012, 134, 2492.

[100] R. Chattot, O. Le Bacq, V. Beermann, S. Kuhl, J. Herranz, S. Henning, L. Kuhn, T. Asset, L. Guetaz, G. Renou, J. Drnec, P. Bordet, A. Pasturel, A. Eychmuller, T. J. Schmidt, P. Strasser, L. Dubau, F. Maillard, Nat. Mater. 2018, DOI: 10.1038/s41563.

[101] S. Henning, J. Herranz, H. Ishikawa, B. J. Kim, D. Abbott, L. Kühn, A. Eychmüller, T. J. Schmidt, J. Electrochem. Soc. 2017, 164, F1136. 
[102] S. Henning, H. Ishikawa, L. Kühn, J. Herranz, E. Müller, A. Eychmüller, T. J. Schmidt, Angew. Chem. Int. Ed. 2017, 56, 10707.

[103] H. L. Liu, F. Nosheen, X. Wang, Chem. Soc. Rev. 2015, 44, 3056.

[104] Y. Iflah, I. Zilbermann, E. Korin, A. Bettelheim, Ecs Electrochem Lett 2013, 2, F55.

[105] X. Zhang, N. Hao, X. Y. Dong, S. B. Chen, Z. Zhou, Y. Zhang, K. Wang, RSC Adv. 2016, 6, 69973.

[106] L. Zhao, Z. B. Wang, J. L. Li, J. J. Zhang, X. L. Sui, L. M. Zhang, Electrochim Acta 2016, 189, 175.

[107] P. P. Song, X. N. Cui, Q. Shao, Y. G. Feng, X. Zhu, X. Q. Huang, J Mater Chem A 2017, 5, 24626.

[108] L. Zhao, Z. B. Wang, J. L. Li, J. J. Zhang, X. L. Sui, L. M. Zhang, RSC Adv. 2015, 5, 98160.

[109] C. Zhu, D. Wen, M. Oschatz, M. Holzschuh, W. Liu, A. K. Herrmann, F. Simon, S. Kaskel, A. Eychmüller, Small 2015, 11, 1430.

[110] Q. R. Shi, C. Z. Zhu, D. Du, C. X. Bi, H. B. Xia, S. Feng, M. H. Engelhard, Y. H. Lin, J Mater Chem A 2017, 5, 19626.

[111] L. Zhao, X.-L. Sui, J.-L. Li, J.-J. Zhang, L.-M. Zhang, Z.-B. Wang, Catal. Comm. 2016, 86, 46.

[112] M. L. Anderson, R. M. Stroud, D. R. Rolison, Nano Lett. 2002, 2, 235.

[113] L. Ren, K. S. Hui, K. N. Hui, J Mater Chem A 2013, 1, 5689.

[114] B. Cai, A. Dianat, R. Hübner, W. Liu, D. Wen, A. Benad, L. Sonntag, T. Gemming, G. Cuniberti, A. Eychmüller, Adv. Mater. 2017, 29, 1605254.

[115] B. Cai, D. Wen, W. Liu, A. K. Herrmann, A. Benad, A. Eychmüller, Angew. Chem. Int. Ed. 2015, 54, 13101.

[116] C. Z. Zhu, Q. R. Shi, S. F. Fu, J. H. Song, D. Du, D. Su, M. H. Engelhard, Y. H. Lin, J Mater Chem A 2018, 6, 7517.

[117] A. Kowal, M. Li, M. Shao, K. Sasaki, M. B. Vukmirovic, J. Zhang, N. S. Marinkovic, P. Liu, A. I. Frenkel, R. R. Adzic, Nat. Mater. 2009, 8, 325.

[118] K. D. Gilroy, A. Ruditskiy, H. C. Peng, D. Qin, Y. Xia, Chem. Rev. 2016, 116, 10414.

[119] X. W. Yu, P. G. Pickup, J Power Sources 2008, 182, 124.

[120] S. Zhang, Y. Shao, G. Yin, Y. Lin, Angew. Chem. Int. Ed. 2010, 49, 2211.

[121] Y. Miura, S. Tsujimura, S. Kurose, Y. Kamitaka, K. Kataoka, T. Sakurai, K. Kano, Fuel Cells 2009, 9, 70.

[122] J. Biener, M. Stadermann, M. Suss, M. A. Worsley, M. M. Biener, K. A. Rose, T. F. Baumann, Energy Environ. Sci. 2011, 4, 656.

[123] S. Tsujimura, A. Nishina, Y. Hamano, K. Kano, S. Shiraishi, Electrochem commun. 2010, 12, 446.

[124] X. Zhang, W. He, R. Zhang, Q. Wang, P. Liang, X. Huang, B. E. Logan, T. P. Fellinger, Chemsuschem 2016, 9, 2788.

[125] D. Wen, W. Liu, A. K. Herrmann, A. Eychmüller, Chem. Eur. J. 2014, 20, 4380.

[126] J. K. Nørskov, T. Bligaard, A. Logadottir, J. R. Kitchin, J. G. Chen, S. Pandelov, U. Stimming, J. Electrochem. Soc. 2005, 152, J23.

[127] S. Anantharaj, S. R. Ede, K. Sakthikumar, K. Karthick, S. Mishra, S. Kundu, ACS Catal. 2016, 6, 8069.

[128] Y. Gu, S. Chen, J. Ren, Y. A. Jia, C. Chen, S. Komarneni, D. Yang, X. Yao, ACS Nano 2018, 12, 245.

[129] M. A. Worsley, S. J. Shin, M. D. Merrill, J. Lenhardt, A. J. Nelson, L. Y. Woo, A. E. Gash, T. F. Baumann, C. A. Orme, ACS Nano 2015, 9, 4698.

[130] W. Zhao, X. Lu, M. Selvaraj, W. Wei, Z. Jiang, N. Ullah, J. Liu, J. Xie, Nanoscale 2018, 10, 9698. 
[131] X. Xu, H. Chu, Z. Zhang, P. Dong, R. Baines, P. M. Ajayan, J. Shen, M. Ye, ACS Appl. Mater. Interfaces 2017, 9, 32756.

[132] X. Xu, H. Liang, F. Ming, Z. Qi, Y. Xie, Z. Wang, ACS Catal 2017, 7, 6394.

[133] X. Zhang, Y. Han, L. Huang, S. Dong, Chemsuschem 2016, 9, 3049.

[134] B. J. Zhu, C. Qu, S. Gao, Z. B. Liang, H. Zhang, R. Q. Zou, Chemcatchem 2018, 10, 1113.

[135] Y. Zhao, X. Xie, J. Zhang, H. Liu, H. J. Ahn, K. Sun, G. Wang, Chem. Eur. J. 2015, 21, 15908.

[136] S. K. Park, D. Y. Chung, D. Ko, Y. E. Sung, Y. Piao, J Mater Chem A 2016, 4, 12720.

[137] Y. Zhang, L. Zuo, L. Zhang, Y. Huang, H. Lu, W. Fan, T. Liu, ACS Appl. Mater. Interfaces 2016, 8, 7077.

[138] A. Liu, L. Zhao, J. Zhang, L. Lin, H. Wu, ACS Appl. Mater. Interfaces 2016, 8, 25210.

[139] S. Reddy, R. Du, L. Kang, N. Mao, J. Zhang, Appl. Catal. B: Environ. 2016, 194, 16.

[140] Y. Shi, W. Gao, H. Lu, Y. Huang, L. Zuo, W. Fan, T. Liu, ACS Sustain. Chem. Eng. 2017, 5, 6994.

[141] T. F. Jaramillo, K. P. Jørgensen, J. Bonde, J. H. Nielsen, S. Horch, I. Chorkendorff, Science 2007, 317, 100.

[142] C. Xia, Q. Jiang, C. Zhao, M. N. Hedhili, H. N. Alshareef, Adv. Mater. 2016, $28,77$.

[143] H. Han, K. M. Kim, H. Choi, G. Ali, K. Y. Chung, Y. R. Hong, J. Choi, J. Kwon, S. W. Lee, J. W. Lee, J. H. Ryu, T. Song, S. Mhin, Acs Catal 2018, 8, 4091.

[144] C. N. Chervin, P. A. DeSario, J. F. Parker, E. S. Nelson, B. W. Miller, D. R. Rolison, J. W. Long, ChemElectroChem 2016, 3, 1369.

[145] L. Wang, F. Song, G. Ozouf, D. Geiger, T. Morawietz, M. Handl, P. Gazdzicki, C. Beauger, U. Kaiser, R. Hiesgen, A. S. Gago, K. A. Friedrich, J. Mater. Chem. A 2017, 5, 3172.

[146] W. Duan, P. Zhang, Y. Xiahou, Y. Song, C. Bi, J. Zhan, W. Du, L. Huang, H. Mohwald, H. Xia, ACS Appl. Mater. Interfaces 2018, 10, 23081.

[147] D. W. Hua, J. Anderson, J. Di Gregorio, D. M. Smith, G. Beaucage, J. Non-Cryst. Solids 1995, 186, 142.

[148] S. Yun, H. J. Luo, Y. F. Gao, RSC Adv. 2014, 4, 4535.

[149] A. V. Rao, S. D. Bhagat, H. Hirashima, G. M. Pajonk, J. Colloid. Interface Sci. 2006, 300, 279.

[150] M. A. Worsley, T. T. Pham, A. Yan, S. J. Shin, J. R. Lee, M. Bagge-Hansen, W. Mickelson, A. Zettl, ACS Nano 2014, 8, 11013. 

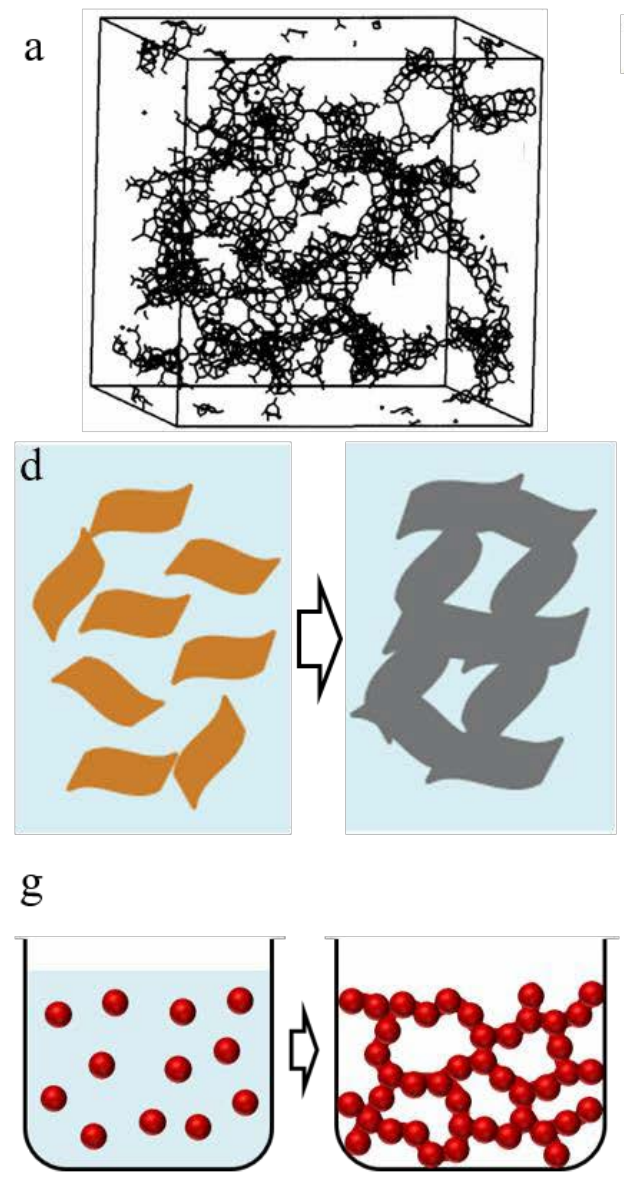

Figure 1. a) Schematic illustration of the molecular aerogel structure taking $\mathrm{SiO}_{2}$ as an example. Reproduced with permission. ${ }^{[147]}$ b) SEM image of a silica aerogel. Reproduced with permission. ${ }^{[148]}$ c) TEM image of silica aerogel showing 3D cross-linked silica chains. Reproduced with permission. ${ }^{[149]}$ d) Schematic gelation process and e) SEM image of the selfassembled graphene gel structure. Reproduced with permission. ${ }^{[22]} \mathrm{f}$ ) TEM image of a graphene aerogel. Reproduced with permission. ${ }^{[150]}$ g) Schematic gelation process, h) SEM image and i) TEM image of the metallic aerogel taking $\mathrm{Pd}_{5} \mathrm{Au}$ as an example. Reproduced with permission. ${ }^{[42]}$ 

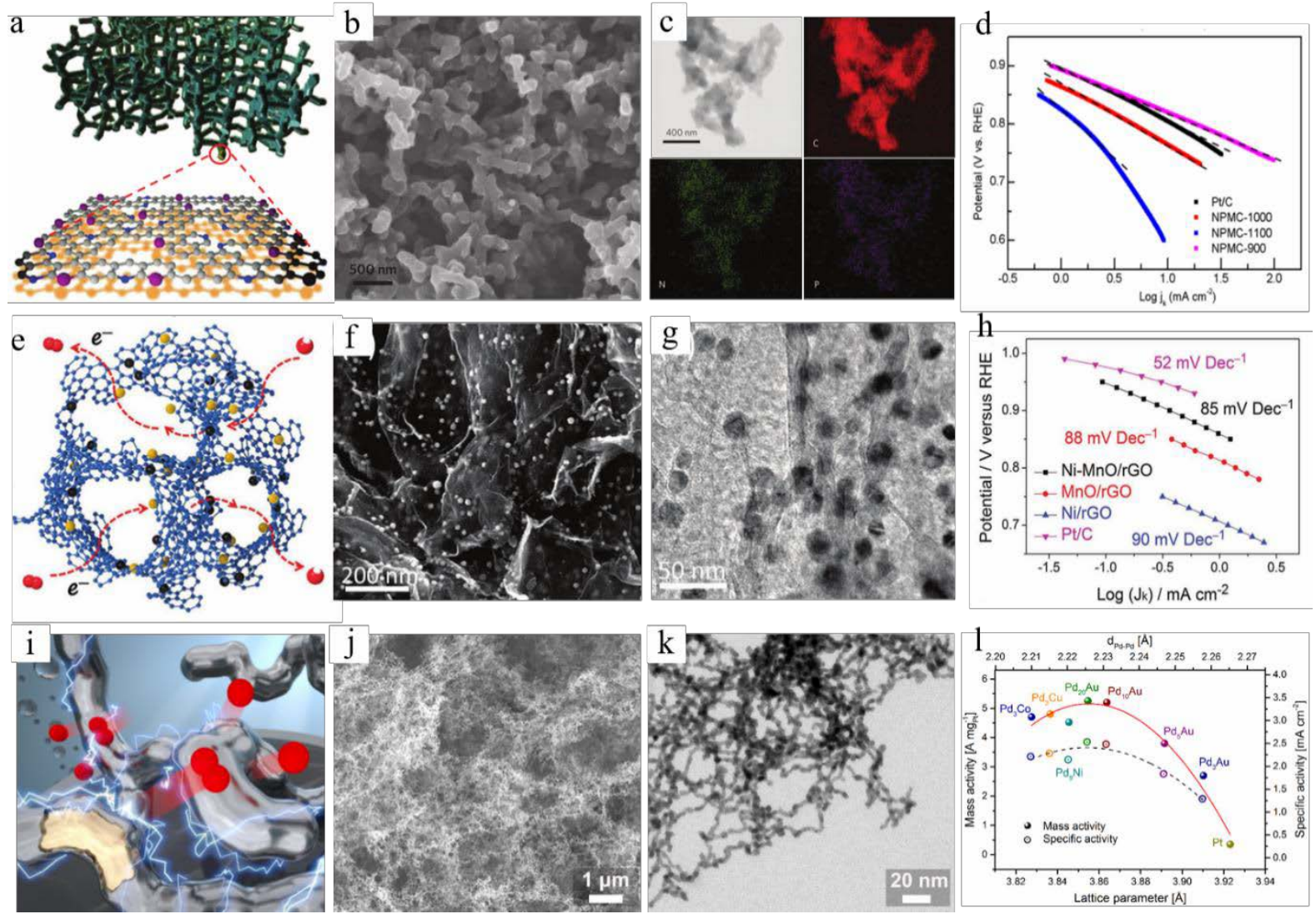

Figure 2. a) Schematic illustration, b) SEM image, and c) TEM and corresponding element maps of the polyaniline-derived N,P-doped carbon aerogel framework (NPMC). d) Tafel curves of the NPMC and Pt/C catalysts obtained in $\mathrm{O}_{2}$-saturated $0.1 \mathrm{M} \mathrm{KOH}$ at $1600 \mathrm{rpm}$ and $10 \mathrm{mV}$ $\mathrm{s}^{-1}$. Reproduced with permission. ${ }^{[65]}$ e) Schematic illustration, f) SEM, and g) TEM images of the Ni-MnO/graphene aerogel. h) Tafel plots of the Ni-MnO/graphene aerogel, $\mathrm{MnO} /$ graphene aerogel, $\mathrm{Ni}$ /graphene aerogel and $\mathrm{Pt} / \mathrm{C}$ catalyst obtained in $\mathrm{O}_{2}$-saturated $0.1 \mathrm{M} \mathrm{KOH}$ at 1600 rpm and $10 \mathrm{mV} \mathrm{s}^{-1}$. Reproduced with permission. ${ }^{[88]}$ i) Schematic illustration, j) SEM, and k) TEM images of the $\mathrm{Pd}_{10} \mathrm{Au}-\mathrm{Pt}$ core-shell aerogel. l) The mass and specific activities of the $\mathrm{Pd}_{\mathrm{x}} M$-Pt core-shell aerogels $(\mathrm{M}=\mathrm{Au}, \mathrm{Ni}, \mathrm{Co}, \mathrm{Cu})$ as a function of the lattice parameter $(a)$ and Pd-Pd intermetallic distance $\left(d_{\mathrm{Pd}-\mathrm{Pd}}\right)$ of the $\mathrm{Pd}_{\mathrm{x}} M$ core aerogels. ORR performances are obtained in $\mathrm{O}_{2}$-saturated $0.1 \mathrm{M} \mathrm{HClO}_{4}$ at $1600 \mathrm{rpm}$ and $10 \mathrm{mV} \mathrm{s}^{-1}$. Reproduced with permission. ${ }^{[42]}$ 

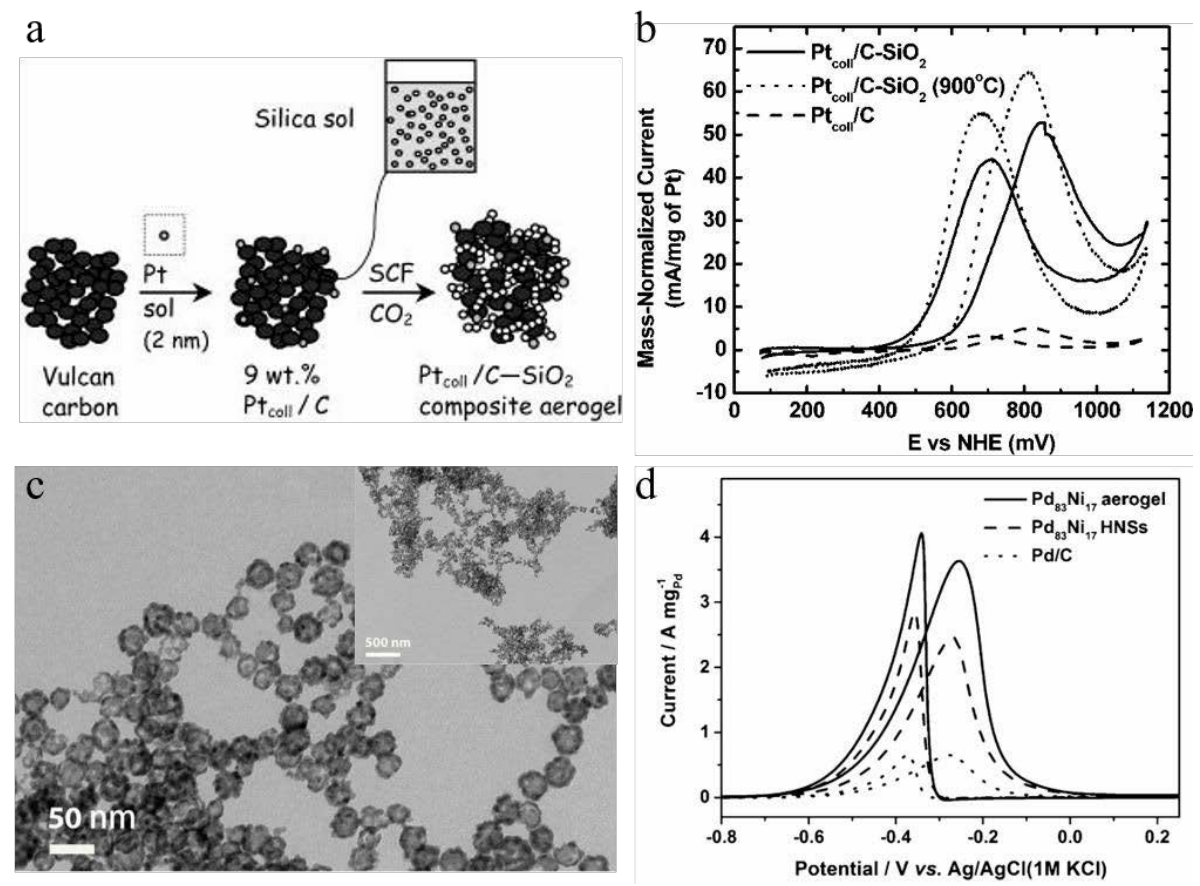

Figure 3. a) Synthesis pathway of silica-reinforced $\mathrm{Pt} / \mathrm{C} / \mathrm{SiO}_{2}$ composite aerogel catalyst. b) Cyclic voltammetry (CV) of the $\mathrm{Pt} / \mathrm{C} / \mathrm{SiO}_{2}$, calcined $\mathrm{Pt} / \mathrm{C} / \mathrm{SiO}_{2}$, and $\mathrm{Pt} / \mathrm{C}$ catalysts in $1 \mathrm{M} \mathrm{MeOH}$ $+1 \mathrm{M} \mathrm{H}_{2} \mathrm{SO}_{4}$ with a scan rate of $5 \mathrm{mV} \mathrm{s}^{-1}$. Reproduced with permission. ${ }^{[112]} \mathrm{c}$ ) TEM images of the $\mathrm{Pd}_{83} \mathrm{Ni}_{17}$ nanoshell-based aerogel at different magnifications. d) Pd-mass-normalized CVs of the aerogel and $\mathrm{Pd} / \mathrm{C}$ catalysts in $1 \mathrm{M} \mathrm{EtOH}+1 \mathrm{M} \mathrm{NaOH}$ with a scan rate of $50 \mathrm{mV} \mathrm{s}{ }^{-1}$. Reproduced with permission. ${ }^{[15]}$ 

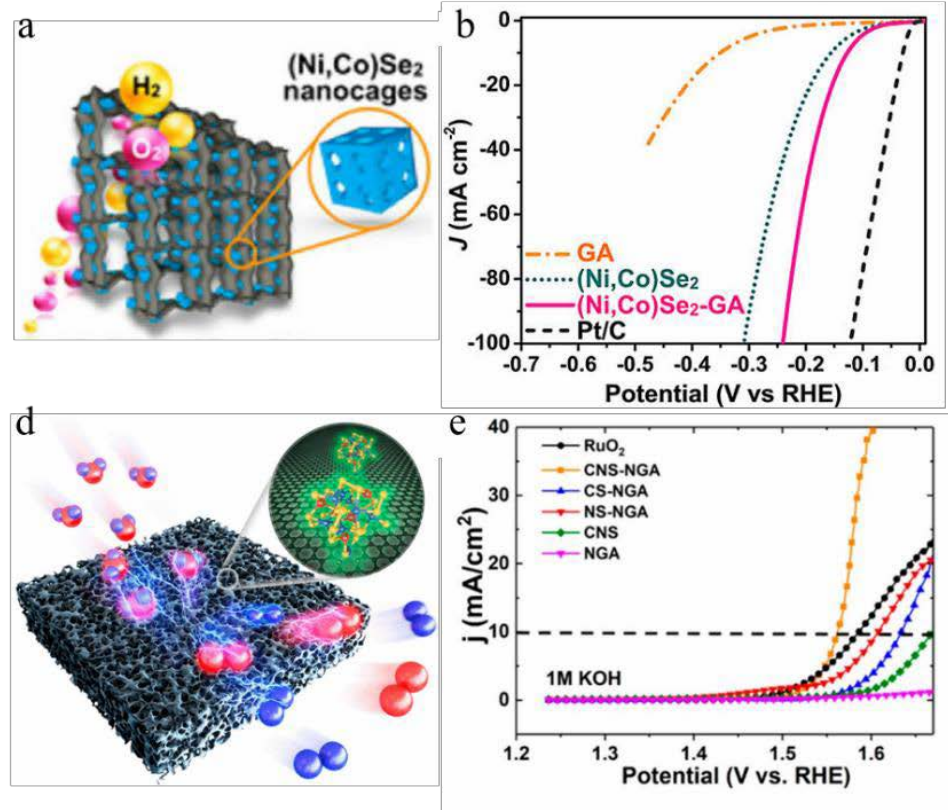
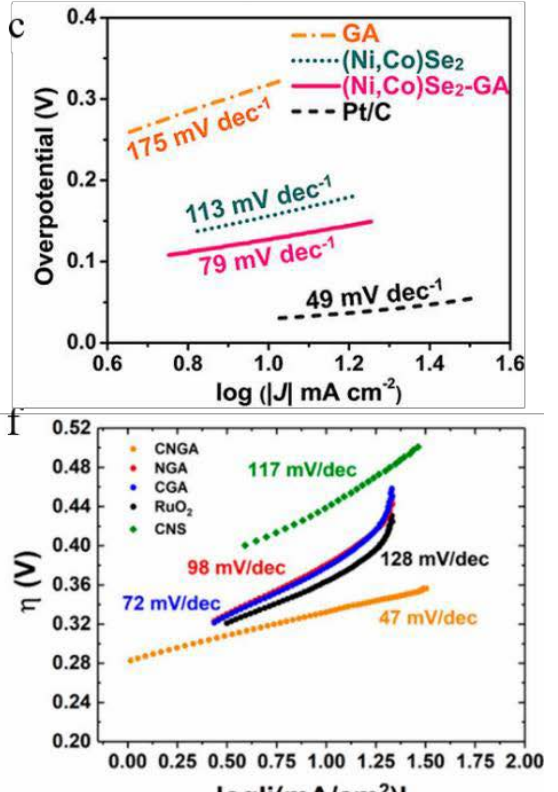

$\log \operatorname{lj}\left(\mathrm{mA} / \mathrm{cm}^{2}\right) \mid$

Figure 4. a) Scheme of the aerogel for catalyzing HER. b) HER polarization curves and c) the corresponding Tafel plots of the (Ni,Co)Se2/graphene aerogel loaded on $\mathrm{Ni}$ foam in $1.0 \mathrm{M} \mathrm{KOH}$. Reproduced with permission. ${ }^{[132]}$ d) Scheme of the aerogel for catalyzing OER. e) OER polarization curves and f) the corresponding Tafel plots of the (Co,Ni) $\mathrm{S}_{2} / \mathrm{N}$-graphene aerogels and the $\mathrm{RuO}_{2}$ catalysts in $\mathrm{O}_{2}$-saturated $1.0 \mathrm{M} \mathrm{KOH}$ at $2000 \mathrm{rpm}$. Reproduced with permission. ${ }^{[143]}$ 


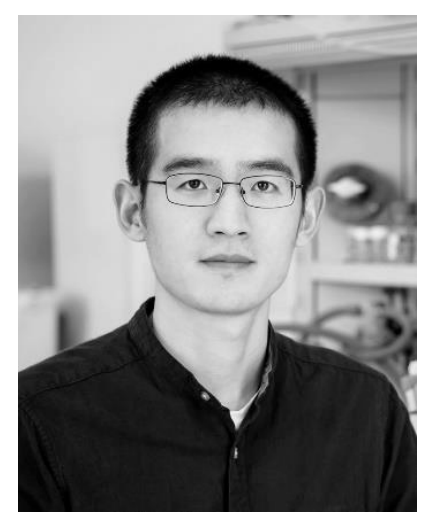

Bin Cai obtained his PhD from Technische Universität Dresden in 2017 under the supervision of Prof. Alexander Eychmüller and MSc from Changchun Institute of Applied Chemistry, Chinese Academy of Sciences in 2014 under the supervision of Prof. Li Niu. Since 2017, he joined Massachusetts Institute of Technology as a postdoc associate under the supervision of Prof. Yang Shao-Horn and Prof. Yuriy Román. His research interest focuses on the synthesis and assembly of nanocrystals and their photo- or electro-catalytic properties.

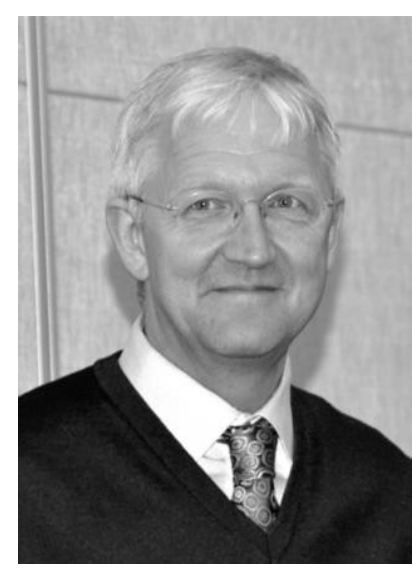

Alexander Eychmüller started his academic career in Göttingen with studies of physics (Ph.D., MPI for Biophysical Chemistry, Prof. A. Weller and Dr. K. H. Grellmann) and continued at UCLA (postdoc with Prof. M. A. El-Sayed), Berlin (HMI with Prof. A. Henglein), and the University of Hamburg (with Prof. H. Weller). Since 2005 he holds the chair in Physical Chemistry at TU Dresden. His research interests include the synthesis and characterization of nanosized objects and their photophysical, electrochemical, and structural properties. 


\section{Table of contents}

Aerogels derived from catalytically active nanomaterials opened tremendous opportunities for electrocatalysis. The integration of nanoscale properties and aerogel features offers desirable combination of high exposure of reactive sites, conducting and self-support skeletons and straightforward mass transfer pathways. Recent advances of the aerogel-based electrocatalysts are summarized in terms of nanocarbons, composites, and pure metals.

Keyword: aerogels, electrocatalysis, porous materials, self-assembly, controlled destabilization

Bin Cai and Alexander Eychmüller*

\section{Promoting Electrocatalysis upon Aerogels}

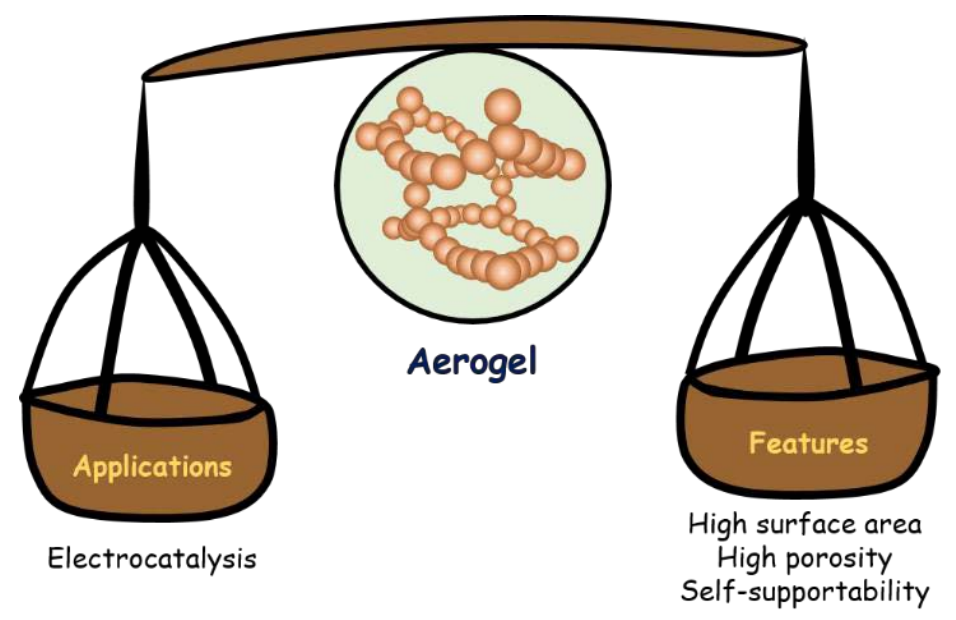

